\title{
Günther Rehme*
}

March 2002

\begin{abstract}
In many OECD countries income inequality has risen, but surprisingly redistribution has as well. The theory attributes this partly to the redistributive effect of education spending. In the model income inequality and growth depend in an inverted U-shaped way on education. To maintain a given level of human capital it is shown that a less efficient schooling technology requires more resources, which lowers pretax and posttax income inequality as well as growth. Using consistently defined income data from the Luxembourg Income Study suggests that there is a negative relationship between growth and income inequality in rich countries. It is argued that using some unadjusted inequality measures in growth regressions may yield estimates that are biased upwards. The evidence suggests that a rich country would raise growth with lower pretax and posttax inequality if it spent more on education.
\end{abstract}

Keywords: growth, redistribution, inequality, education

JEL classification: O4

Copyright $\odot$ author(s) 2002

* Technische Universität Darmstadt

This study is linked to the theme of Growth and Poverty discussed at the WIDER Development Conference, 25-26 May 2001, Helsinki. UNU/WIDER gratefully acknowledges the financial support from the governments of Denmark, Finland and Norway to the 2000-2001 research programme. 
UNU World Institute for Development Economics Research (UNU/WIDER) was established by the United Nations University as its first research and training centre and started work in Helsinki, Finland in 1985. The purpose of the Institute is to undertake applied research and policy analysis on structural changes affecting the developing and transitional economies, to provide a forum for the advocacy of policies leading to robust, equitable and environmentally sustainable growth, and to promote capacity strengthening and training in the field of economic and social policy making. Its work is carried out by staff researchers and visiting scholars in Helsinki and through networks of collaborating scholars and institutions around the world.

UNU World Institute for Development Economics Research (UNU/WIDER)

Katajanokanlaituri 6 B, 00160 Helsinki, Finland

Camera-ready typescript prepared by Günther Rehme and Lorraine Telfer-Taivainen (UNU/WIDER)

Printed at UNU/WIDER, Helsinki

The views expressed in this publication are those of the author(s). Publication does not imply endorsement by the Institute or the United Nations University, nor by the programme/project sponsors, of any of the views expressed.

ISSN 1609-5774

ISBN 92-9190-190-3 (printed publication)

ISBN 92-9190-191-1 (internet publication) 


\title{
(Re-)Distribution of Personal Incomes, Education and Economic Performance Across Countries*
}

\author{
Günther Rehme \\ Technische Universität Darmstadt ${ }^{\dagger}$
}

March 8, 2002

\begin{abstract}
In many OECD countries income inequality has risen, but surprisingly redistribution as well. The theory attributes this partly to the redistributive effect of education spending. In the model income inequality and growth depend in an inverted U-shaped way on education. To maintain a given level of human capital it is shown that a less efficient schooling technology requires more resources, which lowers pre-tax and post-tax income inequality as well as growth. Using consistently defined income data from the Luxembourg Income Study suggests that there is a negative relationship between growth and income inequality in rich countries. It is argued that using some unadjusted inequality measures in growth regressions may yield estimates that are biased upwards. The evidence suggests that a rich country would raise growth with lower pre-tax and post-tax inequality if it spent more on education.
\end{abstract}

Keywords: Growth, Redistribution, Inequality, Education

JEL classification: O4

*I am grateful for helpful comments made by Theo Eicher, Danny Quah, Cecilia GarcíaPeñalosa and the participants at the conferences "Growth and Inequality: Issues and Policy Implications" at CESifo, Munich, and Schloss Elmau, Bavaria, in 2001/2, and the Development Conference on Growth and Poverty at UNU/WIDER in Helsinki, May 2001. I have also benefited from useful conversations with Ingo Barens, Volker Caspari and Rafael Gerke. Furthermore, I owe a special thanks to Rafael Doménech and an anonymous referee for their insightful comments and suggestions. Of course, all errors are my own.

$\dagger$ Correspondence: TU Darmstadt, FB 1/VWL 1, Schloss, D-64283 Darmstadt, Germany. phone: +49-6151-162219; fax: +49-6151-165553; E-mail: rehme@hrzpub.tu-darmstadt.de 


\section{Introduction}

According to Kuznets (1955) an inverted U-shaped relationship between income and inequality should be observed in the course of development. Thus, redistribution which makes the income distribution more unequal should be beneficial in the earlier stages of development. The opposite would hold at later stages of development.

Following Perotti (1996) and the references cited there, the recent theoretical literature on inequality, redistribution and growth can be divided into four main approaches. The fiscal policy approach argues that the income distribution affects growth through its effects on government expenditure and taxation. Due to the disincentive effect on private savings and investment growth decreases as distortionary taxation increases. Redistributive government expenditure and distortionary taxation decrease as equality increases.

The political instability approach argues that in more unequal societies individuals are more prone to engage in rent-seeking activities or other manifestations of sociopolitical instability. As the latter decrease, investment and growth increase. Furthermore, sociopolitical instability decreases as equality increases.

Another strand of the literature stresses the link between borrowing constraints, the distribution of income and wealth and investment in human capital. These models usually show that growth increases as investment in human capital increases. For any given degree of imperfection in the capital market, investment in human capital increases as equality increases.

Related to the latter link some authors concentrate on the connection between education and fertility. Here fertility and schooling decisions are the result of the interplay of the direct cost of raising children and the opportunity cost of the 
parents' human capital. Growth is shown to be higher when investment in human capital is raised, and fertility is lower. In turn, fertility decreases and investment in human capital is raised as equality increases.

All these approaches predict that growth increases as inequality decreases. Indeed a number of studies such as Alesina and Rodrik (1994), Persson and Tabellini (1994) or Perotti (1996) find that growth is negatively associated with income inequality across countries. This has established what may be called the Conventional Consensus View (CCV).

However, based on inequality data compiled by Deininger and Squire (1996) that consensus has been challenged by e.g. Li and Zou (1998), Forbes (2000), or Barro (2000) who find a non-robust or even positive association, especially for rich countries. ${ }^{1}$ These results may therefore be called the New Challenge View $(N C V)$.

Although Banerjee and Duflo (2000) have recently attempted to reconcile the two conclusions, they ended up with a negative result. Based on Deininger and Squire's data and most NCV authors' use of unadjusted inequality measures they show that the data cannot really tell us very much about the relationship between inequality and growth, especially once you account for possible nonlinearities.

Whatever the association between growth and inequality might be, it would entail important consequences for the effect of redistribution on growth. One should bear in mind that income inequality and (income) redistribution are two distinct things. But they are related as follows: The economic system produces an income distribution and then the state intervenes to redistribute income by levying taxes and granting subsidies to satisfy some welfare target. After the

\footnotetext{
${ }^{1}$ Even though these authors are careful to mention that it would be too early to draw policy conclusions from their findings, they call for a reassessment of the relationship. However, their data and their results are based on problematic features. See Atkinson and Brandolini (2001), Rehme (1999) and the discussion below.
} 
state intervention another income distribution emerges that may look quite different from the one before the intervention. The net effect of the intervention is usually called redistribution. Thus, a comparison between the distribution of personal incomes before and after taxes provides one with a picture of the level of redistribution.

The evidence about the link between redistribution and growth across countries is mixed. ${ }^{2}$ Clearly any study which finds that inequality is bad for growth somehow implies that redistribution generating more equality should be beneficial for growth. Of course, the opposite holds when finding a positive association.

For instance, Perotti (1993), Bertola (1993), Alesina and Rodrik (1994) or Persson and Tabellini (1994) show that redistribution causes lower growth. However, empirical studies such as Easterly and Rebelo (1993), Perotti (1994) or Sala-i-Martin (1996) find that there is a positive relation across countries. These results can be reconciled with theory by models along the lines of e.g. Galor and Zeira (1993), Saint-Paul and Verdier (1996), Chiu (1998), Aghion et al. (1999) or Jovanovic (2000).

Much recent research explains these links by skill-biased technical change or by politico-economic arguments. This paper, in turn, focuses on the schooling link and argues that public education, its finance and the way it is undertaken (schooling technology) are important determinants of income inequality and growth. ${ }^{3}$

In the model human capital simultaneously determines growth and income inequality. In this framework the paper identifies two redistribution mechanisms.

\footnotetext{
${ }^{2}$ This literature is surveyed by e.g. Bénabou (1996), Bertola (2000), Aghion, Caroli and García-Peñalosa (1999), or Zweimüller (2000).

${ }^{3}$ Thus, the paper builds on recent research by Eicher and García-Peñalosa (2001) who show that human capital plays a dual role in development due to the interaction between forces of supply and demand for education when there is skill biased technical change. Here the focus is on the education technology itself. For empirical evidence of the link between skill-biased technical change and inequality see e.g. Murphy, Riddel and Romer (1998), Krusell, Ohanian, Ríos-Rull and Violante (2000) or Beaudry and Green (2000).
} 
One the one hand redistribution occurs by means of direct fiscal redistribution from the well-off to the not so well-off. On the other hand there is redistribution through taxes used for expenditure on public education, which redistributes income by changing the relative wages. It is shown that growth and pre-tax and post-tax income inequality - measured by the Gini coefficient - are first increasing and then decreasing in human capital. For a given level of human capital a less efficient education technology implies lower growth, but also lower after-tax income inequality and higher measured income redistribution. The intuition for this is straightforward: To maintain a given level of public education a less efficient education sector requires higher, redistributive taxes. In contrast, a more skill intensive technology does not affect the education sector directly, but it implies higher growth and more inequality and lower measured redistribution for a given level of human capital.

Most of the recent NCV proponents have based their results on unadjusted inequality measures using the secondary data-set of Deininger and Squire (1996). As shown by Atkinson and Brandolini (2001) there are pitfalls when using these data. In particular, they argue (p. 796) that 'there is no real alternative to seeking data-sets where the observations are as fully consistent as possible; at the same time, the choice of definition on which to standardize may affect the conclusions drawn.'

Therefore, this paper uses reliable and consistently defined income data from the Luxembourg Income Study for a sample of relatively rich countries. With these data the model's implications are then set against the empirical evidence. The data suggest the following:

The association between the education as well as the distributional variables and growth is not very strong. More secondary as well as tertiary education or 
more spending on overall education appear to be associated with higher growth. Pre-tax and post-tax income inequality are negatively related to growth, even when controlling for fertility. ${ }^{4}$ Thus, the situation after redistribution is not conducive to growth, suggesting that more redistribution might raise long-run growth. These results remain robust when using larger samples with less consistent inequality data from the World Income Inequality Database (WIID). ${ }^{5}$

The consistently found negative association between growth and inequality of incomes before and after taxes is interpreted in light of research that mixes Gini coefficients for income before and after taxes. It is argued that the coefficients on unadjusted Gini coefficients are most likely to be biased upwards. The implications of that are discussed in the text.

Controlling for standard variables such as initial income or fertility, the data reveal that the government expenditure on (all levels of) education is negatively associated with pre-tax and post-tax income inequality and positively related to redistribution. That suggests a redistributive, but also positive growth effect of education spending.

However, education spending is policy driven and the policies may be very diverse across countries. Under some strong assumptions the data provide suggestive evidence that controlling for education spending and policy interaction, a higher dropout rate in tertiary education, taken as a proxy for a less efficient use of resources for education or for a less productive education sector, imply lower income inequality and redistribution, but also higher growth. In turn, when controlling for the dropout and policy interaction, more education spending is

\footnotetext{
${ }^{4}$ For instance, Barro (2000) finds for his data and for unadjusted inequality measures that inequality is positively associated with growth when looking at a sub-sample of rich countries and when including fertility as an additional control variable.

${ }^{5}$ Similar results are obtained in Rehme (1999) for pre-tax inequality measured by consistently defined inequality data from Deininger and Squire (1996).
} 
associated with less pre-tax and post-tax income inequality and less redistribution but with higher growth.

Thus, the data suggest that the typical (rich) country would have higher growth and less inequality if it spent more on education given its education technology. ${ }^{6}$ If the latter becomes worse, higher inequality and lower growth might ensue, once policy reactions have responded to that change.

The paper is organized as follows: Section 2 presents the theoretical model and derives testable predictions. Section 3 confronts the model with empirical evidence. Section 4 provides concluding remarks.

\section{The Model}

Consider an economy that is populated by $N$ (large) members of two representative dynasties of infinitely lived individuals. The two dynasties are made up of high-skilled people, $L_{h}$, and low-skilled people, $L_{l}$, where $L_{h}, L_{l}$ denote the total numbers of the respective agents in each dynasty. The difference between the agents is "lumpy", that is, either an individual has received education certified in the form of a degree and is then considered high-skilled or it has no degree and remains in the low-skilled labour pool.

By assumption the population is stationary with $L_{h} \equiv x N$ and $L_{l} \equiv(1-x) N$ where $x$ denotes the percentage of high-skilled people in the population. Each individual supplies one unit of either high or low-skilled labour inelastically over time. Furthermore, the high-skilled agents own an equal share of the total capital stock, which is held in the form of shares of many identical firms operating in a world of perfect competition. Thus, high-skilled agents receive wage and capital

\footnotetext{
${ }^{6}$ This finding is a cross-country analogue to recent research by Goodspeed (2000), who shows this to be the case for the U.S. over time.
} 
income and make investment decisions, whereas low-skilled agents do not, as they do not own capital by assumption. ${ }^{7}$

Aggregating over firms overall output is produced according to

$$
Y_{t}=B_{t} K_{t}^{1-\alpha} H^{\alpha}, H^{\alpha}=\left[\left(L_{h}+L_{l}\right)^{\alpha}+\beta L_{h}^{\alpha}\right], \quad 0<\alpha<1,
$$

where $K_{t}$ denotes the aggregate capital stock including disembodied technological knowledge, $H$ measures effective labour in production, and $B_{t}$ is a productivity index. The production function is a reduced form (see Appendix A.2) of the following relationship: By assumption effective labour depends on tasks requiring basic skills and tasks requiring high skills. These tasks are imperfect substitutes in production. On the other hand low and high-skilled people are taken to be perfect substitutes in performing basic tasks. Thus, high-skilled people always perform the tasks of low-skilled people in the model, but low-skilled people can never execute tasks that require a degree. Modelling production in this way relates to work that distinguishes between tasks performed for a given educational attainment of the labour force and education mixes for given tasks. See e.g. Tinbergen (1975), chpt. 5, and Lindbeck and Snower (1996)

The parameter $\beta$ measures skill-biased productivity differences, that is, it captures how productively tasks, which require high skills, contribute to the generation of output in relation to tasks requiring low skills. ${ }^{8}$ Notice that each type

\footnotetext{
${ }^{7}$ This captures two empirical observations: First, the more educated usually derive a larger share of the total capital income than the uneducated. Second, the educated commonly have educated offspring, whereas the uneducated often do not, that is, the proportion of young people who receive higher education whose parents have not is low. For an alternative justification of the assumption in a two period OLG setting see Appendix A.1. It is important to notice that in this model the family background does not determine whether a child receives higher education or not.

${ }^{8} \mathrm{~A}$ constant $\beta$ implies that the diversity in it across countries is structurally fixed for a long time. Thus, the paper abstracts from skill-biased technical change and should, therefore, be viewed as complementary to research along the lines of Galor and Tsiddon (1997), Acemoglu
} 
of labour alone is not taken to be an essential input in production.

The government runs a balanced budget and uses its tax revenues to finance public education and to grant direct transfers to the low-skilled workers. ${ }^{9}$ Thus, the paper contemplates two redistributive mechanisms. On the one hand resources are redistributed directly from the currently working, relatively rich high skilled people to the currently working, relatively poor low skilled individuals. On the other hand there is intertemporal redistribution from the currently working high skilled to the future high skilled individuals whose parents in turn may be low or high skilled.

For this the government taxes the accumulated factor of production, that is, it taxes the high skilled agents' capital income at a constant rate $\vartheta \equiv \tau+\phi$. The capital stock (wealth) of the representative high-skilled agent is $k_{h t}=\frac{K_{t}}{L_{h}}$ so that $G_{t}=\vartheta r_{t} k_{h t} L_{h}=\vartheta r_{t} K_{t}$ where $r_{t}$ denotes the return on capital. This implies that $\frac{G_{t}}{r_{t} K_{t}}=\vartheta$ for all $t$. Thus, real resources $\vartheta r_{t} K_{t}=(\tau+\phi) r_{t} K_{t}$ are taken from the private sector where the amount $\tau r_{t} K_{t}$ is used to finance public education, which generates high-skilled agents. ${ }^{10}$ In turn the amount $\phi r_{t} K_{t}$ is granted as (1998), or Caselli (1999).

${ }^{9}$ Capital income taxes keep the analysis simple and are supposed to capture a broad class of redistributive tax arrangements. For a similar approach in a different context see Alesina and Rodrik (1994). In this context the data appendix provides some evidence that across countries capital income taxes are indeed significantly positively related to expenditure on education. Constancy of the tax rate is imposed in order to focus on long-run, time-consistent equilibria with steady state, balanced growth. For a discussion of private vs. public education see, for instance, Glomm and Ravikumar (1992) or Fernandez and Rogerson (1998).

${ }^{10}$ In the model agents are endowed by the same basic ability and receive basic training which is produced and provided costlessly. Education is always meant to be higher education. Ex ante everybody is a candidate for receiving (higher) education and once chosen to be in the education process will complete the degree. Thus, the education sector is characterized by continuous excess demand due to rationing, which seems realistic for most education systems. Furthermore, the education process is taken to be sufficiently productive in converting no skills into high-skills. The model ignores problems arising from the time spent receiving education by assuming that education is provided as a public good and that all people spend the same time in school, but attend different courses leading to different degrees. Opportunity costs of education might easily be introduced into the model by subtracting a fixed amount of happiness from a high-skilled person for having spent time in school. The paper's results would not change in 
transfers to the low-skilled and captures that the government directly affects the net income distribution by correcting for post-education income differentials.

Of course, redistribution may take other forms in reality. For instance, suppose that in contrast to this model's assumptions education is privately costly. Public expenditures on higher education might then be regressive if higher income families have better access to educational opportunities. Redistribution in the form of social transfers might in fact have a growth impact by loosening liquidity constraints that prevent individuals in poor families from taking advantage of educational opportunities. In that sense redistribution corrects for ex ante (wealth or income) inequality in the paper, because education is provided costlessly and ex ante the family background of a student does not matter in the model. Second, there is redistribution ex post which corrects for inequality in income after education has taken place.

In general, public education depends on government resources and other factors such as high-skilled labour itself. That is captured by the following reduced form of the education technology

$$
x=\left(\frac{\tau}{c}\right)^{\epsilon} \text { where } 0<\epsilon<1, c \geq 1 \quad x_{\tau}>0, \text { and } x_{\tau \tau}<0 .
$$

Thus, if the government channels more resources into education, it will generate more high-skilled people. However, doing this becomes more difficult at the margin, as more resources provided to the education sector lead to a decreasing marginal product of those resources due to congestion effects.

The parameter $c$ measures the efficiency by which government resources are used in education. It captures to what extent public funds ultimately affect that case. Notice that $G_{t}$ is taken to be rising over time. 
education output. One way to think about $\frac{1}{c}$ is as a survival rate in a particular education programme. If the latter is higher it would make funds more efficient when generating graduates and the study times were of equal length.

In turn, $\epsilon$ measures the productivity of the whole education sector. A lower $\epsilon$ implies that the education sector is more productive and that a marginal increase in taxes would increase education output relatively more. ${ }^{11}$ This productivity may depend on the duration of studies, the quality of education, student-teacher ratios or how capital (computers) and students are combined for given resources in efficiency units $\left(\frac{\tau}{c}\right)$.

Underlying equation (2) is the description of an education sector with spillovers from, for instance, high-skilled to new high-skilled people or where the capital equipment such as computers makes the education technology very productive. For a justification of the set-up see Appendix A.3.

The Private Sector. There are as many identical, price-taking firms as individuals and the firms face perfect competition and maximize profits. By assumption they are subject to knowledge spillovers, which take the form $B_{t}=A\left(\frac{K_{t}}{N}\right)^{\eta}=$ $A k_{t}^{\eta}$ with $\eta \geq \alpha$. Thus, the average stock of capital, $k_{t}=\frac{K_{t}}{N}$, which includes disembodied technological knowledge, is the source of a positive externality. ${ }^{12}$ Then simplify by setting $\eta=\alpha$ which allows one to concentrate on steady state behaviour. For a justification see Romer (1986). As the firms cannot influence the

\footnotetext{
${ }^{11}$ The reduced form directly relates the percentage of high-skilled people $(x)$ to the percentage of efficiently used resources (wealth) going into the education sector $\left(\tilde{\tau} \equiv \frac{\tau}{c}\right)$. If $p r=\frac{x}{\tilde{\tau}}=\tilde{\tau}^{\epsilon-1}$ denotes the productivity of the education sector in terms of efficiently used resources, then $\mathrm{pr}$ is decreasing in $\epsilon$ for given policy.

${ }^{12}$ Here the assumption is that regardless of the source of new ideas or blueprints production is undertaken so that all agents are affected relatively equally from knowledge spillovers. The results would not change if the externality depended on the entire capital stock instead.
} 
externality, it does not enter their decision directly so that

$$
\begin{aligned}
& r=(1-\alpha) A k_{t}^{\alpha} K_{t}^{-\alpha} H^{\alpha}, \\
& w_{h}=\alpha A k_{t}^{\alpha} K_{t}^{1-\alpha}\left[\left(L_{h}+L_{l}\right)^{\alpha-1}+\beta L_{h}^{\alpha-1}\right], \\
& w_{l}=\alpha A k_{t}^{\alpha} K_{t}^{1-\alpha}\left(L_{h}+L_{l}\right)^{\alpha-1} .
\end{aligned}
$$

All agents act price-takingly and have logarithmic utility. The low-skilled do not invest and consume their entire wage and transfer income so that their intertemporal utility is given by ${ }^{13}$

$$
\int_{0}^{\infty} \frac{c_{l}^{1-\nu}-1}{1-\nu} e^{-\rho t} d t \quad \text { where } \quad c_{l}=w_{l}+\phi r \frac{K}{L_{l}}
$$

In contrast, the high-skilled own all the assets which are collateralized one-to-one by capital. A representative high-skilled agent takes the paths of $r, w_{h}, w_{l}, \vartheta$ as given and solves

$$
\begin{array}{ll} 
& \max _{c_{h}} \int_{0}^{\infty} \frac{c_{h}^{1-\nu}-1}{1-\nu} e^{-\rho t} d t \\
\text { s.t. } \quad & \dot{k_{h}}=w_{h}+(1-\vartheta) r k_{h}-c_{h} \\
& k_{h}(0)=\text { given, } k_{h}(\infty)=\text { free. }
\end{array}
$$

This problem is standard and involves the following growth rate of consumption

$$
\gamma \equiv \frac{\dot{c_{h}}}{c_{h}}=\frac{(1-\vartheta) r-\rho}{\nu}
$$

which depends on the after-tax return on capital. As the high-skilled agents own the initial capital stock equally and as they have identical utility functions, their investment decisions are the same. But then the wealth distribution will not

\footnotetext{
${ }^{13}$ From now time subscripts are dropped for convenience.
} 
change over time and only high-skilled agents continue to own equal shares of the total capital stock over time.

Market Equilibrium. For the rest of the paper normalize the population by setting $N=1$ so that the factor rewards in (3) are given by

$$
r=(1-\alpha) A\left(1+\beta x^{\alpha}\right), \quad w_{h}=\alpha A k_{t}\left(1+\beta x^{\alpha-1}\right) \quad \text { and } \quad w_{l}=\alpha A k_{t} .
$$

The return on capital is constant over time and wages grow with the capital stock. Note that $w_{l}(t)$ does not directly depend on $x$. It only does so indirectly through $k_{t}$ and so $\gamma(x)$ when $t \neq 0$. It is frequently shown that an increase in human capital raises the wages of the low-skilled. In this model such an increase (higher $x$ ) would not affect the low-skilled people's wages initially. But over time it would either raise the wage flow when $x<\hat{x}$ and growth is raised, or lower it when growth is reduced by too much human capital substituting for low-skilled people. $^{14}$

As $w_{h}=w_{l}\left(1+\beta x^{\alpha-1}\right)$, high-skilled labour receives a premium over what their low-skilled counterpart gets, regardless of whether high skilled labour is taken as scarce - as in most models - or not. This reflects that the high-skilled may always (perfectly) substitute for low-skilled labour so that both types of labour receive the same wage $w_{l}$ for routine tasks and that performing high-skilled tasks is remunerated by the additional amount $w_{l} \beta x^{\alpha-1}$. The wage premium depends on the percentage of high-skilled labour in the population, grows over time at the

\footnotetext{
${ }^{14}$ It is often argued that human capital raises the wages of the low-skilled due to the complementarity of these two (usually assumed essential) labour inputs in production. See e.g. Ciccone, Peri and Almond (1999). Here neither input is essential in production and any observed reaction of more high-skilled people is attributed to the indirect effect that capital exerts on the wages of the low-skilled. See e.g. Johnson (1984). Thus, more human capital is taken to have a stronger immediate impact on the wages of the high-skilled than on the wages of the low-skilled. For empirical evidence on this see e.g. Büttner and Fitzenberger (1998).
} 
rate $\gamma$ and is decreasing in $x$ for a given capital stock. ${ }^{15}$

On the other hand the (relative) wage premium $\frac{w_{h}}{w_{l}}$ increases when production is getting more (high-)skill biased (higher $\beta$ ). This feature of the model is in line with explanations which attribute the recent increase in wage inequality in the U.S.A. to skill biased technological change. The latter is often shown to have had a stronger impact on the U.S. distribution of wages than the observed increase in the number of high-skilled people. Notice, however, that the U.S. experience is not shared by many other countries where the wage premium has remained relatively flat, but the number of high-skilled people has also increased. One explanation of the latter experience would be to attribute this to a cancellation of the counteracting effects of $\beta$ and $x .^{16}$

From the production function one immediately gets $\gamma_{y}=\gamma_{k}$ so that for given $x$ per capita output and the capital-labour ratio grow at the same rate. With constant $N$ and $x$ total output also grows at the same rate as the aggregate capital stock. From (6) the consumption of the representative high-skilled agent grows at $\gamma$. Each high-skilled worker owns $k_{h 0}=\frac{K_{0}}{L_{h}}$ units of the initial capital stock. Equation $(5 \mathrm{~b})$ implies $\dot{k_{h}}=w_{h}+(1-\vartheta) r k_{h}-c_{h}$ so that $\gamma_{k_{h}}=\frac{w_{h}-c_{h}}{k_{h}}-(1-\vartheta) r$ where $(1-\vartheta) r$ is constant. In steady state, $\gamma_{k_{h}}=\gamma_{k}$ is constant by definition. But $\frac{w_{i}}{k}, i=h, l$ is constant as well, because from (7)

$$
\frac{w_{h}}{k_{t}}=\frac{\alpha A k_{t}\left(1+\beta x^{\alpha-1}\right)}{k_{t}}=\alpha A\left(1+\beta x^{\alpha-1}\right) \text { and } \frac{w_{l}}{k_{t}}=\alpha A,
$$

which implies $\gamma_{k}=\gamma$. But then consumption of the low-skilled also grows at the

\footnotetext{
${ }^{15}$ The wage premium depends negatively on the number of high-skilled people, which captures an important and realistic aspect in the explanation of wage inequality. See, for instance, Bound and Johnson (1992), Katz and Murphy (1992) or Autor, Krueger and Katz (1998).

${ }^{16}$ The idea that skill biased technological change within firms with its corresponding demand for high-skilled labour and the (education system's) supply of high-skilled people are in a 'run' determining wage inequality over time can e.g. be found in Tinbergen (1975).
} 
rate $\gamma$. Thus, the economy is characterized by balanced growth in steady state with $\gamma_{Y}=\gamma_{K}=\gamma_{y}=\gamma_{k}=\gamma_{c_{h}}=\gamma_{c_{l}}$. From (6), (7) and $\tau=c x^{\frac{1}{\epsilon}}$ one obtains

$$
\gamma=\frac{\left(1-c x^{\frac{1}{\epsilon}}-\phi\right)(1-\alpha) A\left(1+\beta x^{\alpha}\right)-\rho}{\nu}
$$

which is first increasing and then decreasing, that is, concave in $x .{ }^{17}$ Thus, in the model it is possible that an economy has high-skilled workers, but does not necessarily do better than another economy with less high-skilled people.

For given $x \in(0,1)$ the effect of a change in the productivity of the education sector is given by $\frac{d \gamma}{d \epsilon}=\frac{\ln (x) c x^{\frac{1}{\epsilon}} r}{\epsilon^{2} \nu}<0$. One also verifies $\frac{d \gamma}{d c}<0$ and $\frac{d \gamma}{d \beta}>0$ for given $x$. Furthermore, the direct transfers to the low-skilled workers are unproductive in the model and granting more of them (higher $\phi$ ) leads to lower growth.

Proposition 1 The long-run growth rate $\gamma$ is first increasing and then decreasing in $x$. For given $x$, a less productive education technology (higher $\epsilon$ ) or a less efficient use of public resources in education (higher c) imply lower growth, whereas a more skill-biased technology (higher $\beta$ ) implies higher growth. An increase in direct, purely redistributive transfers to the low-skilled (higher $\phi$ ) lowers long-run growth.

Income Inequality. When relating growth to income inequality one should look at an average of incomes over time. But data for such averages are rarely available. Thus, the paper concentrates on simple inequality measures for current income such as the Lorenz curve and the Gini coefficient, because these concepts

\footnotetext{
${ }^{17}$ This follows because $\frac{d \gamma}{d x}=\frac{1}{\nu}\left[-\Delta_{1}+\Delta_{2}\right]$ where $\Delta_{1}=\frac{c}{\epsilon} x^{\frac{1}{\epsilon}-1}(1-\alpha) A\left(1+\beta x^{\alpha}\right)$ and $\Delta_{2}=$ $\left(1-c x^{\frac{1}{\epsilon}}-\phi\right)(1-\alpha) A \alpha \beta x^{\alpha-1}$. For $x \rightarrow 0$ we have $\frac{d \gamma}{d x}=+\infty$. When $x \rightarrow 1$ we have $\frac{d \gamma}{d x}=-\frac{1}{\epsilon} c(1-a) A(1+\beta)+(1-c \phi)(1-\alpha) A \alpha \beta<0$. Furthermore, $\frac{d \Delta_{1}}{d x}>0$ and $\frac{d \Delta_{2}}{d x}<0$ imply $\frac{d^{2} \gamma}{d x^{2}}<0$. These properties capture that expanding education may lead to lower growth under some, especially congestive circumstances. See, for example, Temple (1999), p. 140.
} 
have been used extensively in the recent growth literature. ${ }^{18}$ Note that average current income before $(g)$ and after $(n)$ taxes depends on time and is given by $\mu^{g} \equiv w_{l}(1-x)+w_{h} x+r k_{t}$ and $\mu^{n} \equiv w_{l}(1-x)+\phi r k_{t}+w_{h} x+(1-\phi-\tau) r k_{t}$. However, the gross and net income shares of the low-skilled are constant and given by

$$
\begin{gathered}
\sigma_{l}^{g} \equiv \frac{w_{l t}(1-x)}{\mu_{t}^{g}}=\frac{\alpha(1-x)}{1+\beta x^{a}} \\
\sigma_{l}^{n} \equiv \frac{w_{l t}(1-x)+\phi r k_{t}}{\mu_{t}^{n}}=\frac{\alpha(1-x)+\phi(1-\alpha)\left(1+\beta x^{a}\right)}{\left(1+\beta x^{a}\right)\left(1-(1-\alpha) c x^{\frac{1}{\epsilon}}\right)}
\end{gathered}
$$

where use has been made of $\tau=c x^{\frac{1}{\epsilon}}$. The corresponding Lorenz Curve (LC), which relates population shares to income shares, is presented in Figure 1.

Figure 1: Ordinary Lorenz Curve

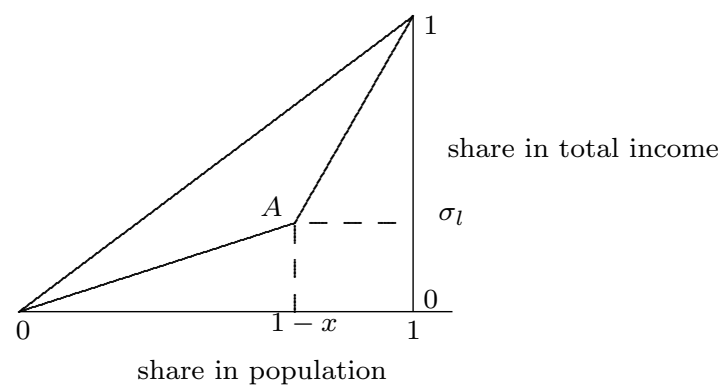

The LC has a kink at the point $A$ at which $(1-x)$ percent of the population receive $\sigma_{l}$ percent of total income. The Gini coefficient is then calculated as

$$
G=1-2\left[\frac{(1-x) \sigma_{l}}{2}+x \sigma_{l}+\frac{\left(1-\sigma_{l}\right) x}{2}\right]=1-\left(\sigma_{l}+x\right)
$$

where the expression in square brackets represents the area under the LC.

\footnotetext{
${ }^{18}$ For a discussion of problems caused by using current income and a measure such as the Gini coefficient in a world where income is growing, see e.g. Shorrocks (1983), Fields (1987), or Amiel and Cowell (1999).
} 
It is easy to see that $\sigma_{l}^{n}>\sigma_{l}^{g}$ so that the low-skilled get a larger share of income after taxes than before taxes. If point $A$ corresponds to the situation before taxation then the income distribution after taxes would have a kink at a point strictly above $A$ and would imply a less unequal income distribution. See Atkinson (1970). Furthermore, the Gini coefficients for gross $\left(G^{g}\right)$ and for net $\left(G^{n}\right)$ incomes, i.e.

$$
G^{g}=1-\left(\sigma_{l}^{g}+x\right) \text { and } G^{n}=1-\left(\sigma_{l}^{n}+x\right)
$$

would report that as well, because $\sigma_{l}^{n}>\sigma_{l}^{g}$ implies $G^{g}>G^{n}$. Thus, taxation for education as well as direct transfers have a long-run redistributive impact reflected in the difference between the respective Gini coefficients. For that reason the paper uses (see e.g. Lambert (1993), chpt. 2)

Definition 1 (Redistribution) Income redistribution is measured by $\Pi \equiv G^{g}-$ $G^{n}$ and captures the long-run redistributive impact of taxation used for education and of the direct transfers granted to the low-skilled workers.

As a lot of current empirical growth research employs Gini coefficients for the measurement of income inequality, the definition appears to be a natural one to make. The difference in Gini coefficients is related to the income shares and given by

$$
\Pi=\sigma_{l}^{n}-\sigma_{l}^{g}=\frac{(1-\alpha)\left(\phi\left(1+\beta x^{\alpha}\right)+\alpha(1-x) c x^{\frac{1}{\epsilon}}\right)}{\left(1+\beta x^{\alpha}\right)\left(1-(1-\alpha) c x^{\frac{1}{\epsilon}}\right)} .
$$

Growth, inequality and redistribution are complicated functions of $x$ in the model. In order to get an impression of its qualitative features I have calibrated the model using the paper's data for 13 OECD countries. Focusing on the per- 
centage of the population with tertiary education, which ranges from 10 to 26 percent with a sample mean of 15 percent, the following table presents simulations based on 'reasonable' parameter values.

Table 1: Numerical Simulation

\begin{tabular}{lccccc}
\hline$x$ & $G^{g}$ & $G^{n}$ & $\Pi$ & $\gamma$ & $\tau$ \\
\hline 0.10 & 0.386 & 0.342 & 0.044 & 0.0195 & 0.027 \\
0.15 & 0.392 & 0.345 & 0.047 & 0.0201 & 0.054 \\
0.20 & 0.390 & 0.339 & 0.051 & 0.0202 & 0.089 \\
0.25 & 0.382 & 0.327 & 0.056 & 0.0200 & 0.131 \\
0.30 & 0.370 & 0.310 & 0.059 & 0.0194 & 0.179 \\
\hline
\end{tabular}

Parameter values:

$\alpha=0.7, \beta=1.13, c=1.43, \epsilon=0.58$

$\phi=0.13, \nu=3.55, \rho=0.01$

Thus, income inequality - as measured by the Gini coefficient - as well as growth first increases, and then decreases with a rising number of people with tertiary education. ${ }^{19}$ These simulated effects are small. In particular, they are smaller for the growth rate than for the distributional variables.

Clearly, measured redistribution is higher if the government directly transfers more resources to the low-skilled (higher $\phi$ ). However, in the relevant range measured redistribution is also increasing in $x$ and hence in $\tau$. But there is no clear (functional) relation between inequality and redistribution. For instance, when plotting $\Pi(x)$ against $G^{g}(x)$, it would be possible that two values of $\Pi$ are associated with the same $G^{g}$. Furthermore, higher $x$ implies higher redistribution $\Pi$ but also first higher and then lower growth.

\footnotetext{
${ }^{19}$ In an economy with income growth such as the one modelled here this property of the Gini coefficients often follows by construction. See Fields (1987).
} 
Proposition 2 For a given production and education technology and many parameter constellations $(\beta, c, \epsilon)$,

1. the Gini coefficients $\left(G^{g}, G^{n}\right)$ for pre-tax or post-tax income inequality are inverted $U$-shaped in $x$.

2. two economies with $x_{1}>x$ may be characterized by $G_{1}^{g}=G^{g}$ but $\Pi_{1}>\Pi$ and $\gamma_{1} \gtreqless \gamma$.

Thus, for sufficiently high $x$ an increase in it would lower pre-tax and post-tax income inequality. Furthermore, such an increase would often also widen the gap between them and with it redistribution as defined here.

As $x$ is an increasing function of $\tau$ for given parameters it follows that income inequality is also inverted U-shaped in $\tau$. However, for the rest of the theoretical analysis it is convenient to continue to work with $x$. Thus, the subsequent analysis is phrased conditional on $x$, bearing in mind that $x(\tau(i), i)$ where $i$ are exogenously given, economically important fundamentals like the model's $\alpha$ or $\epsilon$.

These results, esp. the simulation results have to interpreted with some caution as they are sensitive to changes in the institutional and production features. Using (9), (10) and (11) one obtains for parametric changes

$$
\begin{array}{r}
\frac{d \sigma_{l}^{n}}{d \beta}<\frac{d \sigma_{l}^{g}}{d \beta}<0, \quad \frac{d G^{n}}{d \beta}>\frac{d G^{g}}{d \beta}>0 \Rightarrow \frac{d \Pi}{d \beta}<0 \\
\frac{d \sigma_{l}^{n}}{d c}>0, \frac{d \sigma_{l}^{g}}{d c}=0, \quad \frac{d G^{n}}{d c}<0, \frac{d G^{g}}{d c}=0 \Rightarrow \frac{d \Pi}{d c}>0 \\
\frac{d \sigma_{l}^{n}}{d \epsilon}>0, \frac{d \sigma_{l}^{g}}{d \epsilon}=0, \quad \frac{d G^{n}}{d \epsilon}<0, \frac{d G^{g}}{d \epsilon}=0 \Rightarrow \frac{d \Pi}{d \epsilon}>0
\end{array}
$$

Proposition 3 For a given level of human capital (x),

1. a more skill-biased production (higher $\beta$ ) entails higher pre-tax and (even) higher post-tax inequality and so lower redistribution. 
2. a less efficient use of public resources in education (higher c) or a less productive education sector (higher $\epsilon$ ) imply no change in pre-tax, but a reduction in post-tax inequality and hence more redistribution.

The first result follows because a higher $\beta$ has a direct and positive bearing on the wages of the high-skilled and pre-tax capital income, but has no direct effect on tax revenues. As a consequence there is lower redistribution. The intuition for the second result is the following: If it is relatively more difficult to generate more high-skilled people, higher taxes are called for. Thus, if two economies have the same $x$ the one with a less productive education sector must use more resources to have that $x$, thereby redistributing relatively more income. ${ }^{20}$

The last result captures how differences in economic fundamentals may shape the education-distribution-growth nexus. For instance, suppose two economies have similarly productive education systems, $\epsilon=\epsilon_{1}$, have the same level of human capital and equal $\phi$ s. Assume that country 1 uses a more skill-biased technology $\beta_{1}>\beta=1$, but uses public funds less efficiently $c_{1}>c=1$. Then depending on the relative magnitude of $c_{1}$ and $\beta_{1}$, country 1 definitely exhibits more pre-tax income inequality, but may be observed to redistribute more or less income.

\footnotetext{
${ }^{20}$ Recall that the result is conditional on $x$. Given that policy may react to a change in fundamentals there is nothing to preclude the possibility that a change in them produces different effects in total. Notice also that the result applies only when income inequality is measured by the Gini coefficient. For instance, a higher $\epsilon$ may increase income inequality (given $\tau$ ) when measuring it by the concept of Generalized Lorenz Curve Dominance. See Shorrocks (1983). Thus, the results depend on which measurement concept one uses.
} 


\section{Empirical Evidence}

\subsection{Data and Methodology}

Human capital is measured by the percentage of the population from 25 to 64 years of age which has attained at least upper secondary education (SECP) or at least university-level (tertiary) education (TERP). Data for these variables are provided by the OECD for 1996 and 34 countries. They collapse the time series dimension into a single number by attaching weights to the human capital composition of different generations at a particular point in time and are taken to represent a long-run process which is approximated by their time-averages over the sample period. ${ }^{21}$

The nature of the human capital data also serves as a justification for the methodology employed. Although authors such as Caselli, Esquivel and Lefort (1996) argue that growth should be investigated by means of dynamic panel data methods, these methods may have their own problems as e.g. argued by Barro (1997), p. 37, or Temple (1999), p. 132 and analyzed by Banerjee, Marcellino and Osbat (2000). Therefore, the paper uses time averaged data and concentrates on simple statistics, the properties of which may also be relevant for more sophisticated methods.

Valuable sources for data on income distributions for many countries are the Luxembourg Income Study (LIS) and the secondary data-set of the World Income Inequality Database (WIID). Both satisfy many minimum quality requirements. But given that LIS provides a consistent data source which features as a large

\footnotetext{
${ }^{21}$ Notice the binary nature of the variables. Breaking them down by age cohorts reveals that in almost all countries these percentages have risen over time. For a critical assessment of other frequently employed data sources measuring human capital see de la Fuente and Doménech (2000).
} 
subset of the WIID, income inequality is measured by Gini coefficients based on LIS data first. ${ }^{22}$

In an intertemporal framework one should measure inequality in long-run incomes. That would require calculating time-averages of incomes. Gini coefficients of such averages for large samples of countries do not exist. As an approximation I take averages of Gini coefficients over time and interpret those averages as the Gini coefficient of an average of income distributions at different dates. Here averages of Gini coefficients for each country are taken for the period 1970-90 and are meant to reflect long-run within-country inequality. ${ }^{23}$

The income and recipient concept employed here is gross or net income per household where the latter has been adjusted by the square root of household members. For the LIS data these concepts are strictly adhered to.

For instance, Deininger and Squire (1998), Forbes (2000), Barro (2000), Banerjee and Duflo (2000), and others construct unadjusted inequality measures by taking averages of Gini coefficients based on gross or net income or adjusted (add 6 percentage points) Gini coefficients based on expenditure, each for individual or household income recipients, for each country and year according to some data quality criteria. That procedure may yield large samples, but a lot of important information is lost. On the importance of income and recipient concepts in the measurement of inequality see, for instance, Cowell (1995) or Atkinson (1983).

\footnotetext{
${ }^{22}$ Another valuable source is the data-set compiled by Deininger and Squire (1996) which forms a subset of WIID. Although their data-set covers more countries than LIS, it has many problematic features that are discussed in detail by Atkinson and Brandolini (2001). Furthermore, note that LIS satisfies all the quality requirements of Deininger and Squire, namely that the data be based on (1) actual observation of individual units drawn from household surveys, (2) a representative sample covering all of the population, and (3) comprehensive coverage of different income sources as well as population groups.

${ }^{23}$ Based on their own data-set Deininger and Squire (1998) also run their regressions on an average of Gini coefficients for the whole sample period. For the justification, which is satisfied here as well, see p. 268 of their paper. Thus, growth is not predicted to depend just on the initial income distribution.
} 
The paper's strict adherence to the income and recipient concepts minimizes measurement error, but leads to a small sample. However, as a sensitivity check results are also presented which are based on WIID data with some inconsistencies that lead to larger samples.

Finally, long-run growth rates were calculated using the Penn World Table (Mark 5.6) from Summers and Heston (1991). All the other data are taken from Barro and Lee (1994). Combining these data sources with LIS data yields a sample of 13 relatively rich countries for the period 1970-90 for which reliable (good) inequality data are available.

\section{$3.2 \quad$ Findings}

For the LIS data the Gini coefficient for individual households' gross incomes is denoted by LIS.G and that for individual households' net incomes by LIS.N. Furthermore, RE $\equiv$ LIS.G - LIS.N denotes redistribution. In the sample the Gini coefficients are characterized as follows:

Over the sample period income inequality has risen in some countries, but not in all. Redistribution has increased in almost all. For instance, in the U.S. the Gini coefficient went up from 35.05 in 1974 to 41.81 in 1997. Thus, there was a marked increase in pre-tax income inequality. For the same period the Gini coefficient for net income goes up from 31.46 in 1974 to 37.24 in 1997. On the other hand redistribution (RE) goes up from 3.59 in 1974 to 4.57 in 1997. Thus, policy in the U.S. has corrected slightly increasingly for some of the increase in pre-tax inequality. A similar picture holds for the UK so that higher inequality in pre-tax incomes often seems to be associated with more redistribution within countries over time.

In France pre-tax income inequality has fallen over time, but redistribution 
has fallen too. Sweden has low pre-tax inequality which fell over the period (1967: 32.05; 1995: 26.2). It reduced redistribution from 6 in 1967 to 4.2 in 1995. Thus, Sweden and the U.S. have very different pre-tax income inequality, but redistribute approximately the same.

On period averages the U.S. redistributes more (RE: 4.4) than e.g. Germany (RE: 3.7), France (RE: 2.49) or Canada (RE: 3.4). All the latter countries have lower pre-tax inequality than the U.S. In Canada pre-tax inequality is low and has hardly changed over the sample period. However, redistribution increased, especially since the late 80s (RE 1971: 2.8; RE 1994: 4.3).

Due to the small sample size most of the simple correlations between the variables turn out to be statistically insignificant. Somewhat surprisingly the simple correlation between pre-tax income inequality LIS.G and redistribution RE is negative and quite low (-0.08), suggesting that countries with higher inequality redistribute less. However, the relationship is only negative when approximated linearly (OLS) but it is U-shaped when approximated by a cubic spline function. ${ }^{24}$ This would confirm recent studies by e.g. Bénabou (2000), Lee and Roemer (1998), or Figini (1999).

Clearly, growth of GDP per capita should be controlled for by many factors. This is done here by means of simple growth regressions and by focussing on parsimonious models. Following a common procedure, a benchmark model with often used robust regressors is used to add education and distributional variables to see what the latter contribute to the 'explanation' of long-run growth across countries.

\footnotetext{
${ }^{24}$ The descriptive statistics and details of the empirical results are presented in the appendix.
} 


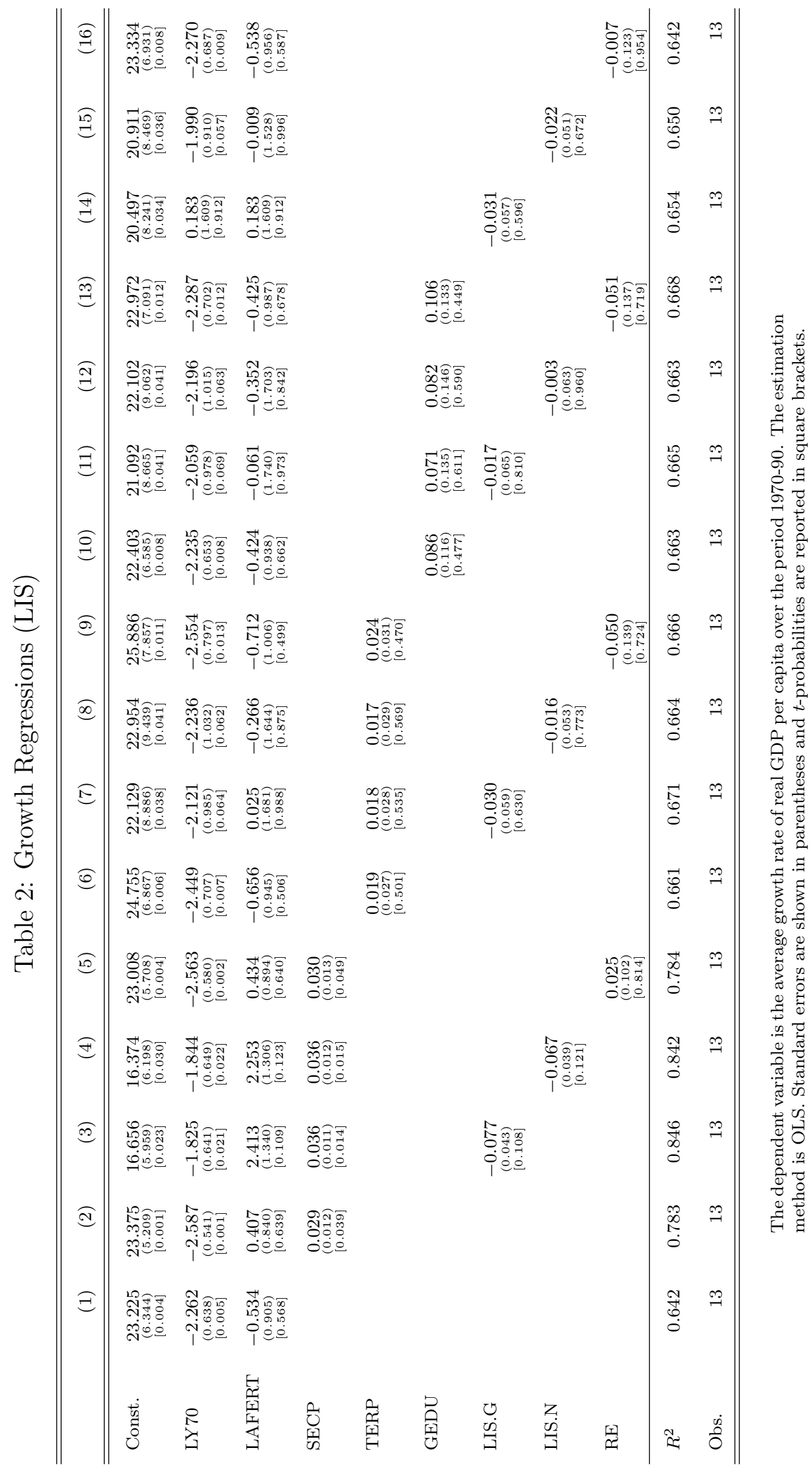


The benchmark model used here for $i$ countries is $\gamma_{i}=\alpha+\beta_{1} \mathrm{LY}_{70}+$ $\beta_{2}$ LAFERT $_{i}+\beta_{3}$ CVLIB $_{i}+\epsilon_{i}$ where LY70 denotes the (natural) logarithm of GDP per capita in 1970, LAFERT represents the logarithm of the average fertility rate for the period 1960-84, CVLIB is Gastil's index of civil liberties (from 1 to $7 ; 1=$ most freedom) for the period $1972-89$ and $\epsilon_{i}$ is a disturbance term. According to the estimated coefficients CVLIB does not really add to the 'explanation' of growth and is dropped in the subsequent analysis, because it is not the main variable of interest. ${ }^{25}$

In Table 2 model (1) is the reduced benchmark model. In all models the estimated coefficient on LY70 is always negative and that on fertility (LAFERT) is negative in ten out of the sixteen models. The estimates then suggest the following:

The association between the human capital variables as well as the distributional variables and growth is not very strong. Most of the coefficients on these variables are statistically insignificant. However, even small effects may have important and economically significant consequences in the long run. ${ }^{26}$ Bearing in mind that due to the consistency requirement the sample size is small and although given statistical insignificance the focus of this paper is on the point estimates and their economic significance, but not on inferential statistics.

1) The coefficients on education are positive in all models. However, secondary education (SECP) appears to contribute more to linear 'explanations' of long-run growth than tertiary education (TERP) or education expenditure (GEDU). As an indication notice the relatively high $R^{2} \mathrm{~s}$ in models (2)-(5). For instance, the latter models suggest that an increase of one standard deviation

\footnotetext{
${ }^{25}$ The estimate for $\beta_{3}$ was 0.082 with a standard error of 0.378 and a $t$-probability of 0.832 .

${ }^{26}$ On the distinction between statistical and economic significance see e.g. McCloskey (1985) or McCloskey and Ziliak (1996).
} 
(11 percentage points) in the percentage of people aged 25-65 who have at least upper secondary education (SECP) raises long-run growth by 0.3 to 0.4 percentage points. Models (6)-(9) suggest that growth would be raised by 0.08 to 0.1 percentage points when increasing by one standard deviation (4.8 percentage points) the percentage of people aged 25-65 who have at least tertiary education (TERP). In turn, a one-standard-deviation change (1.04 percentage points) of more education expenditure would increase the growth rate by around 0.08 to 0.1 percentage points.

2) The coefficients on redistribution (RE) are ambiguous and statistically insignificant. When controlling for SECP they are positive, but they are negative in all other cases. All coefficients on RE suggest that it does not add much to 'explaining' the cross-country variation in growth rates over the sample period.

3) When controlling for initial income and fertility, the coefficients on pretax and on post-tax income inequality are statistically insignificant but they are always negative, no matter whether one also controls for education (SECP, TERP, or GEDU). For instance, when controlling for secondary education SECP in models (2)-(5) a one-standard-deviation change in pre-tax inequality (LIS.G) of 3.67 lowers the long-run growth rate by 0.28 percentage points. The same change for post-tax inequality (LIS.N) amounts to 3.88 and lowers the growth rate by 0.26 . Barro (2000) p. 18 and Perotti (1996) report similar magnitudes for these effects.

But when controlling for tertiary education (TERP) or overall spending on education (GEDU) these effects become quite smaller. E.g. in model (11) which controls for GEDU a one-standard-deviation change in LIS.G (LIS.N) reduces the growth rate by only $0.06(0.01)$ percentage points.

4) Pre-tax income inequality (LIS.G) appears to be more strongly, negatively 
related to growth than post-tax income inequality (LIS.N). ${ }^{27}$

These findings suggest that more inequality in gross incomes seems to imply lower growth for the typical country in the sample. Then the state intervenes by redistribution. That intervention does not appear to affect growth very much in the typical country. However, the resulting inequality in personal incomes after taxes is still negative. But that means that the state may not have intervened enough to generate a situation where after-tax income inequality would not negatively affect growth anymore.

The negative association between pre-tax or post-tax income inequality and growth also allows for an interpretation of results based on some forms of unadjusted inequality measures. See Appendix A.5.

Lemma 1 If the 'true' association between growth and pre-tax income inequality, measured by the Gini coefficient, is negative, then the estimated coefficients on unadjusted inequality measures based on mixes of Gini coefficients for $\underline{\text { net }}$ and for gross incomes are most likely to be biased upwards.

This means that the estimated non-negative signs found on the coefficients for unadjusted inequality measures used in the growth regressions of Barro (2000) or Forbes (2000) allow for another interpretation: The 'true' association between pre-tax inequality and growth is negative. Post-tax inequality depends on pre-tax inequality and redistribution. If you use the mix-generated unadjusted inequality measure, you really run a regression on a variable containing information about pre-tax inequality and redistribution, which - as argued before - are two different, although related things. Thus, a positive coefficient in a growth regression may

\footnotetext{
${ }^{27}$ This may be discerned from Table 2 when comparing the estimated coefficients for pre-tax (LIS.G) and post-tax inequality (LIS.N). The ones for the latter are consistently smaller and closer to zero than those found for LIS.G.
} 
also indicate that pre-tax inequality negatively 'affects' growth and redistribution strongly positively 'affects' growth. Given this interpretation the call for a reassessment of the inequality-growth relationship may be premature.

Determinants of Inequality. The theory argues that education spending determines human capital which in turn shapes the relationship between income inequality and growth. Table 3 presents the 'effects' of some widely used determinant factors of income inequality and redistribution.

Table 3: Determinants of Inequality (LIS)

\begin{tabular}{|c|c|c|c|c|c|c|c|c|c|}
\hline & (1) & $(2)$ & (3) & (4) & (5) & (6) & (7) & $(8)$ & (9) \\
\hline $\begin{array}{c}\text { Dependent } \\
\text { Variable }\end{array}$ & LIS.G & LIS.G & LIS.G & LIS.N & LIS.N & LIS.N & $\mathrm{RE}$ & $\mathrm{RE}$ & $\mathrm{RE}$ \\
\hline Const. & $\begin{array}{c}-87.562 \\
(36.683) \\
{[0.038]}\end{array}$ & $\begin{array}{c}-79.199 \\
(35.545) \\
{[0.053]}\end{array}$ & $\begin{array}{c}-43.246 \\
(42.709) \\
{[0.341]}\end{array}$ & $\begin{array}{c}-104.390 \\
(41.330) \\
{[0.030]}\end{array}$ & $\begin{array}{c}-92.394 \\
(37.240) \\
{[0.035]}\end{array}$ & $\begin{array}{c}-59.485 \\
(45.991) \\
{[0.232]}\end{array}$ & $\begin{array}{c}14.814 \\
(17.153) \\
{[0.408]}\end{array}$ & $\begin{array}{c}11.109 \\
(16.805) \\
{[0.525]}\end{array}$ & $\begin{array}{l}13.734 \\
(22.422) \\
{[0.557]}\end{array}$ \\
\hline LY70 & $\begin{array}{l}10.903 \\
(3.687) \\
{[0.014]}\end{array}$ & $\begin{array}{l}10.627 \\
(3.527) \\
{[0.015]}\end{array}$ & $\begin{array}{l}7.789 \\
(3.939) \\
{[0.083]}\end{array}$ & $\begin{array}{l}12.268 \\
(4.154) \\
{[0.014]}\end{array}$ & $\begin{array}{l}11.872 \\
(3.695) \\
{[0.011]}\end{array}$ & $\begin{array}{l}9.275 \\
(4.241) \\
{[0.060]}\end{array}$ & $\begin{array}{l}-1.158 \\
(1.724) \\
{[0.517]}\end{array}$ & $\begin{array}{l}-1.035 \\
(1.668) \\
{[0.550]}\end{array}$ & $\begin{array}{l}-1.243 \\
(2.068) \\
{[0.565]}\end{array}$ \\
\hline LAFERT & $\begin{array}{l}23.036 \\
(5.236) \\
{[0.001]}\end{array}$ & $\begin{array}{l}21.910 \\
(5.066) \\
{[0.002]}\end{array}$ & $\begin{array}{l}18.214 \\
(5.519) \\
{[0.011]}\end{array}$ & $\begin{array}{l}23.728 \\
(5.899) \\
{[0.002]}\end{array}$ & $\begin{array}{l}22.114 \\
(5.307) \\
{[0.002]}\end{array}$ & $\begin{array}{c}18.730 \\
(5.943) \\
{[0.014]}\end{array}$ & $\begin{array}{c}-0.525 \\
(2.448) \\
{[0.835]}\end{array}$ & $\begin{array}{c}-0.026 \\
(2.395) \\
{[0.992]}\end{array}$ & $\begin{array}{l}-0.296 \\
(2.897) \\
{[0.921]}\end{array}$ \\
\hline CVLIB & & & $\begin{array}{c}-3.163 \\
(2.289) \\
{[0.204]}\end{array}$ & & & $\begin{array}{c}-2.896 \\
(2.465) \\
{[0.274]}\end{array}$ & & & $\begin{array}{l}-0.231 \\
(1.202) \\
{[0.852]}\end{array}$ \\
\hline GEDU & & $\begin{array}{c}-0.876 \\
(0.626) \\
{[0.195]}\end{array}$ & $\begin{array}{c}-1.438 \\
(0.722) \\
{[0.081]}\end{array}$ & & $\begin{array}{c}-1.256 \\
(0.655) \\
{[0.088]}\end{array}$ & $\begin{array}{c}-1.771 \\
(0.777) \\
{[0.052]}\end{array}$ & & $\begin{array}{l}0.388 \\
(0.296) \\
{[0.222]}\end{array}$ & $\begin{array}{l}0.347 \\
(0.379) \\
{[0.387]}\end{array}$ \\
\hline$R^{2}$ & 0.660 & 0.720 & 0.774 & 0.620 & 0.730 & 0.770 & 0.051 & 0.204 & 0.207 \\
\hline Obs. & 13 & 13 & 13 & 13 & 13 & 13 & 13 & 13 & 13 \\
\hline
\end{tabular}

OLS. Standard errors in parentheses and $t$-probabilities in square brackets.

These regressions indicate that initial income and fertility are negatively related to equality and redistribution. Interestingly, less civil liberties (higher CVLIB) correlate positively with equality and negatively with redistribution. In turn, government spending on overall education (GEDU) is consistently negatively associated with pre-tax and post-tax inequality, but it is positively related to 
redistribution. For instance, according to model (3), (6) and (9) a one-standard deviation change (1.04 percentage points) in GEDU lowers pre-tax inequality (LIS.G) by 1.5 percentage points, lowers post-tax inequality (LIS.N) by 1.8 percentage points and raises measured redistribution by 0.4 percentage points.

\subsection{Sensitivity Analysis}

In order to check whether the results carry over to less stringently defined data I have used Gini coefficients for pre-tax and post-tax income provided by the World Income Inequality Database (WIID). ${ }^{28}$ Only those coefficients of the dataset were used that are representative of all areas and the population of a country. The major difference from LIS is that now the data come from various sources. In a first step only those entries were considered where the income recipient was the household, unadjusted for its composition. In a second step a data-set was created which does not distinguish whether and how the households have been adjusted for their composition. Both procedures yield larger data-sets but the results based on them are very similar. Therefore, I will only report the ones for the first procedure here.

One difficulty with these data is that one cannot easily tell what redistribution is, because the coefficients for gross and net income do not necessarily match. It is possible that the time average of all the Gini coefficients for gross income of a country, now called AIHG, are unrealistically smaller than those for net income, called AIHN. In order to be as consistent as possible, I have only considered a

\footnotetext{
${ }^{28}$ Another sensitivity check would have been to break the LIS data up into 5 or 10 year intervals in order to see if the results remain robust for shorter time periods. Unfortunately, this would have led to extremely small data-sets, making regression analysis almost impossible. Furthermore, the paper's focus is on the long-run and it is, therefore, left an open question whether inequality and growth may be positively associated in the not so long run. For an analysis relating inequality and growth over different time spans see e.g. Forbes (2000).
} 
country's coefficients that match in terms of time and source for the determination of the redistribution variable RE. Interestingly, most of the entries then turn out to originate from LIS, but for unadjusted households.

One advantage of being less stringent is that the sample size increases by up to 70 percent. Table 4 presents growth regressions using the WIID data.

Most of the coefficients are statistically insignificant. This holds even for so called robust regressors such as fertility (LAFERT) and initial income (LY70). The latter are, however, negatively related to growth in the majority of regressions.

The educational variables (SECP, TERP, GEDU) are generally positively related to growth, unless one controls for post-tax income inequality (AIHN). However, the most important finding is that as with the LIS data the variables for pre-tax inequality (AIHG) as well as those for post-tax inequality (AIHN) and redistribution (RE) are negatively related to growth. The negative coefficients on income inequality are generally more statistically insignificant than when using the LIS data. Furthermore, the linear fits of most models are doing badly. As an indication notice the $\mathrm{R}^{2} \mathrm{~s}$ that are quite lower than the ones reported in Table 2. 


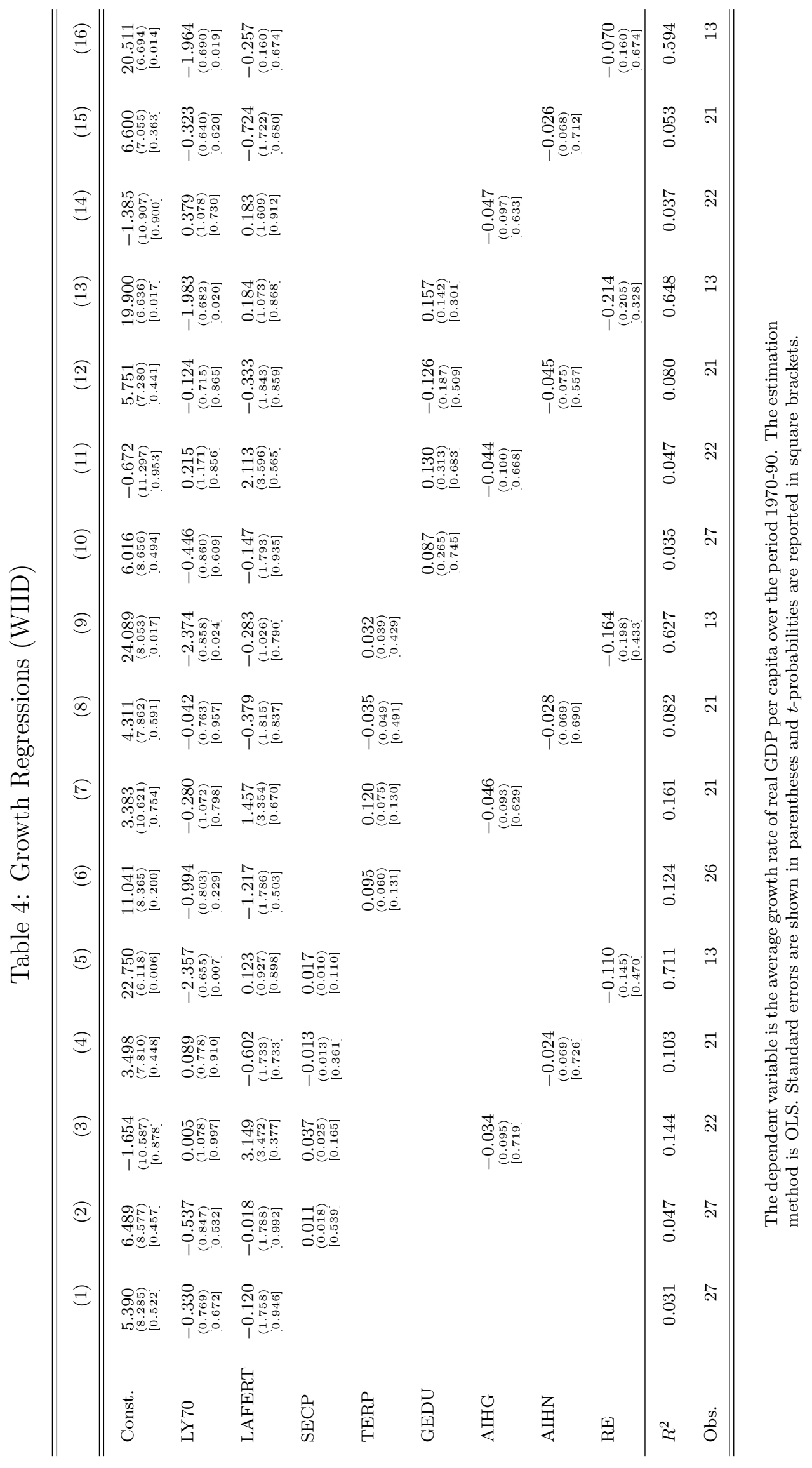


The next table presents the results for the determinants of inequality. Here the fits have quite high $\mathrm{R}^{2} \mathrm{~s}$ but still most variables are statistically insignificant. Initial income (LY70) and fertility (LAFERT) are positively associated with pre-tax (AIHG) and post-tax inequality (AIHN). In contrast to the LIS data redistribution is now positively related to LY70 and LAFERT. See Table 3. The important finding here is that the correlation between education spending (GEDU) and pre-tax as well as post-tax income inequality is negative and that between GEDU and redistribution is positive. ${ }^{29}$

As mentioned before all the results based on the WIID also hold when one does not distinguish whether and how the households have been adjusted for their composition.

Table 5: Determinants of Inequality (WIID)

\begin{tabular}{|c|c|c|c|c|c|c|c|c|c|}
\hline & (1) & $(2)$ & (3) & (4) & (5) & (6) & (7) & (8) & (9) \\
\hline $\begin{array}{c}\text { Dependent } \\
\text { Variable }\end{array}$ & AIHG & AIHG & AIHG & AIHN & AIHN & AIHN & $\mathrm{RE}$ & $\mathrm{RE}$ & $\mathrm{RE}$ \\
\hline Const. & $\begin{array}{c}-39.657 \\
(24.116) \\
{[0.117]}\end{array}$ & $\begin{array}{c}-40.871 \\
(24.886) \\
{[0.118]}\end{array}$ & $\begin{array}{c}-56.856 \\
(32.009) \\
{[0.094]}\end{array}$ & $\begin{array}{c}27.493 \\
(23.435) \\
{[0.256]}\end{array}$ & $\begin{array}{c}17.104 \\
(23.098) \\
{[0.469]}\end{array}$ & $\begin{array}{c}5.635 \\
(24.115) \\
{[0.818]}\end{array}$ & $\begin{array}{c}-12.468 \\
(12.625) \\
{[0.347]}\end{array}$ & $\begin{array}{c}-9.142 \\
(10.357) \\
{[0.400]}\end{array}$ & $\begin{array}{c}-19.033 \\
(11.097) \\
{[0.125]}\end{array}$ \\
\hline LY70 & $\begin{array}{l}5.525 \\
(2.209) \\
{[0.022]}\end{array}$ & $\begin{array}{l}5.831 \\
(2.401) \\
{[0.026]}\end{array}$ & $\begin{array}{l}7.275 \\
(3.014) \\
{[0.027]}\end{array}$ & $\begin{array}{l}-0.777 \\
(2.199) \\
{[0.728]}\end{array}$ & $\begin{array}{l}0.839 \\
(2.295) \\
{[0.719]}\end{array}$ & $\begin{array}{l}1.655 \\
(2.322) \\
{[0.486]}\end{array}$ & $\begin{array}{l}1.145 \\
(1.285) \\
{[0.287]}\end{array}$ & $\begin{array}{l}0.807 \\
(1.077) \\
{[0.473]}\end{array}$ & $\begin{array}{l}1.500 \\
(1.063) \\
{[0.196]}\end{array}$ \\
\hline LAFERT & $\begin{array}{l}28.187 \\
(5.195) \\
{[0.000]}\end{array}$ & $\begin{array}{l}28.089 \\
(5.322) \\
{[0.000]}\end{array}$ & $\begin{array}{l}28.492 \\
(5.398) \\
{[0.000]}\end{array}$ & $\begin{array}{l}14.504 \\
(4.850) \\
{[0.008]}\end{array}$ & $\begin{array}{l}15.317 \\
(4.636) \\
{[0.004]}\end{array}$ & $\begin{array}{l}14.016 \\
(4.630) \\
{[0.008]}\end{array}$ & $\begin{array}{l}2.945 \\
(1.761) \\
{[0.125]}\end{array}$ & $\begin{array}{l}2.991 \\
(1.433) \\
{[0.066]}\end{array}$ & $\begin{array}{l}4.169 \\
(1.479) \\
{[0.023]}\end{array}$ \\
\hline CVLIB & & & $\begin{array}{l}1.066 \\
(1.322) \\
{[0.431]}\end{array}$ & & & $\begin{array}{l}1.960 \\
(1.454) \\
{[0.197]}\end{array}$ & & & $\begin{array}{l}1.143 \\
(0.676) \\
{[0.129]}\end{array}$ \\
\hline GEDU & & $\begin{array}{c}-0.279 \\
(0.737) \\
{[0.710]}\end{array}$ & $\begin{array}{l}-0.085 \\
(0.783) \\
{[0.915]}\end{array}$ & & $\begin{array}{l}-0.949 \\
(0.556) \\
{[0.106]}\end{array}$ & $\begin{array}{c}-0.464 \\
(0.651) \\
{[0.486]}\end{array}$ & & $\begin{array}{l}0.441 \\
(0.178) \\
{[0.035]}\end{array}$ & $\begin{array}{c}0.653 \\
(0.205) \\
{[0.013]}\end{array}$ \\
\hline$R^{2}$ & 0.781 & 0.783 & 0.791 & 0.738 & 0.776 & 0.799 & 0.220 & 0.536 & 0.658 \\
\hline Obs. & 22 & 22 & 22 & 21 & 21 & 21 & 13 & 13 & 13 \\
\hline
\end{tabular}

OLS. Standard errors in parentheses and $t$-probabilities in square brackets.

\footnotetext{
${ }^{29}$ The same conclusion can be reached when controlling for secondary (SECP) or tertiary education (TERP) instead of education spending (GEDU). See the data appendix.
} 
The sensitivity checks therefore suggest the following for the different data: Being less consistent in the definition of key variables in order to get a larger sample and sharper results does not turn out to be a successful strategy. The results based on the consistent data are broadly sharper in that the regression coefficients are usually more statistically significant and the regressions feature higher $\mathrm{R}^{2} \mathrm{~s}$. But for both data-sets the association between distribution and growth as well as distribution and education (finance) is generally found to be statistically insignificant. However, there is some indication that income inequality before and after taxes but also redistribution as measured here is bad for long-run growth. Furthermore, more education and more resources spent on it are usually found to be beneficial for long-run growth. They also seem to reduce income inequality and are positively related to redistribution.

\subsection{The Role of the Schooling Technology}

A common measure of the (internal) inefficiency in schooling is the dropout rate of students enrolled in particular educational programmes. Recently, the OECD has provided data on dropout rates for students enrolled at the university-level tertiary education, covering many OECD countries for the 1990s. ${ }^{30}$ These data are used here under the heroic assumption that differences in these rates reflect structural differences that have not changed much across countries and over a long time horizon. Furthermore, it should be viewed as a composite index depending on $c$ and $\epsilon$. Thus, the results below depend on these assumptions and are therefore only suggestive.

\footnotetext{
${ }^{30}$ The World Bank and UNESCO also provide data on these rates for some countries, but unfortunately only up to 8th grade and excluding important countries like the U.S. For more information consult: www.worldbank.org/data/wdi2000/pdf s/tab2_11.pdf and unescostat.unesco.org/en/stats/stats0.htm.
} 
Dropout rates are available for ten of the countries in the LIS sample. In order to relate consistently to the earlier findings based on the larger LIS sample of 13 countries, the dropout rates for Norway, Sweden and Canada have been set at the average dropout rate (30.1) of the sample excluding these countries. The data appendix shows that all the results below would remain valid when working with the reduced LIS sample of ten countries. Furthermore, it discusses the sensitivity of the results to other interpolations.

Table 6 presents regression results when controlling for policy changes by means of interaction terms. These capture how differences in structure affect differences in policy.

Table 6: Determinants of Inequality and Growth 2 (LIS)

\begin{tabular}{|c|c|c|c|c|c|c|c|c|}
\hline & (1) & (2) & (3) & (4) & (5) & (6) & (7) & (8) \\
\hline $\begin{array}{c}\text { Dependent } \\
\text { Variable }\end{array}$ & LIS.G & LIS.G & LIS.N & LIS.N & $\mathrm{RE}$ & $\mathrm{RE}$ & G70-90 & G70-90 \\
\hline Constant & $\begin{array}{l}68.567 \\
(20.248) \\
{[0.008]}\end{array}$ & $\begin{array}{r}93.025 \\
(44.176) \\
{[0.065]}\end{array}$ & $\begin{array}{l}60.354 \\
(23.019) \\
{[0.028]}\end{array}$ & $\begin{array}{l}84.5688 \\
(46.297) \\
{[0.101]}\end{array}$ & $\begin{array}{l}8.960 \\
(5.833) \\
{[0.159]}\end{array}$ & $\begin{array}{l}10.267 \\
(12.523) \\
{[0.434]}\end{array}$ & $\begin{array}{l}0.635 \\
(3.795) \\
{[0.871]}\end{array}$ & $\begin{array}{l}-6.650 \\
(7.605) \\
{[0.405]}\end{array}$ \\
\hline DROP & $\begin{array}{l}-1.123 \\
(0.583) \\
{[0.086]}\end{array}$ & $\begin{array}{l}-1.753 \\
(1.403) \\
{[0.243]}\end{array}$ & $\begin{array}{c}-0.958 \\
(0.663) \\
{[0.183]}\end{array}$ & $\begin{array}{c}-1.538 \\
(1.470) \\
{[0.323]}\end{array}$ & $\begin{array}{c}-0.190 \\
(0.168) \\
{[0.288]}\end{array}$ & $\begin{array}{l}-0.274 \\
(0.398) \\
{[0.509]}\end{array}$ & $\begin{array}{l}0.044 \\
(0.109) \\
{[0.696]}\end{array}$ & $\begin{array}{l}0.270 \\
(0.242) \\
{[0.293]}\end{array}$ \\
\hline TERP & $\begin{array}{c}-3.117 \\
(1.663) \\
{[0.094]}\end{array}$ & & $\begin{array}{l}-2.879 \\
(1.890) \\
{[0.162]}\end{array}$ & & $\begin{array}{c}-0.305 \\
(0.479) \\
{[0.540]}\end{array}$ & & $\begin{array}{l}0.194 \\
(0.312) \\
{[0.550]}\end{array}$ & \\
\hline TERP*DROP & $\begin{array}{l}0.094 \\
(0.048) \\
{[0.083]}\end{array}$ & & $\begin{array}{l}0.085 \\
(0.055) \\
{[0.155]}\end{array}$ & & $\begin{array}{l}0.011 \\
(0.014) \\
{[0.438]}\end{array}$ & & $\begin{array}{c}-0.006 \\
(0.009) \\
{[0.520]}\end{array}$ & \\
\hline GEDU & & $\begin{array}{c}-12.267 \\
(8.871) \\
{[0.200]}\end{array}$ & & $\begin{array}{c}-11.549 \\
(9.297) \\
{[0.246]}\end{array}$ & & $\begin{array}{l}-1.104 \\
(2.515) \\
{[0.671]}\end{array}$ & & $\begin{array}{l}1.938 \\
(1.527) \\
{[0.236]}\end{array}$ \\
\hline GEDU*DROP & & $\begin{array}{l}0.353 \\
(0.284) \\
{[0.245]}\end{array}$ & & $\begin{array}{l}0.319 \\
(0.298) \\
{[0.312]}\end{array}$ & & $\begin{array}{l}0.047 \\
(0.081) \\
{[0.572]}\end{array}$ & & $\begin{array}{l}-0.061 \\
(0.049) \\
{[0.246]}\end{array}$ \\
\hline$R^{2}$ & 0.309 & 0.265 & 0.216 & 0.291 & 0.269 & 0.248 & 0.147 & 0.235 \\
\hline Obs. & 13 & 13 & 13 & 13 & 13 & 13 & 13 & 13 \\
\hline
\end{tabular}

OLS. Standard errors in parentheses and $t$-probabilities in square brackets.

Means: $\mu_{\mathrm{TERP}}=14.80, \mu_{\mathrm{GEDU}}=5.62, \mu_{\mathrm{DROP}}=30.1$

In terms of the paper's theory the coefficients on these terms can take any 
$\operatorname{sign}^{31}$

The regressions indicate that most of the relationships are statistically insignificant. The point estimates in turn suggest that when controlling for the dropout rate and for policy reactions, more education and more spending on it may raise growth (G70-90) and reduce income inequality, but also redistribution. However, when taking account of policy reactions, that is, when looking at the total effect of education expenditure GEDU (tertiary education, TERP) around the sample mean, it turns out that policy is such that more education expenditure GEDU (tertiary education, TERP) seems to lower income inequality but raises redistribution and growth. ${ }^{32}$

The coefficients on the drop-out rate DROP appear to confirm that countries where it is more difficult to generate education have lower inequality. But they also seem to be those that redistribute less. But the latter is only true if one controls for the interaction terms. The total effect is that around the sample mean an increase in DROP raises pre-tax and post-tax inequality but lowers redistribution and growth.

In terms of the model this suggests that $c$ and $\epsilon$ may not be independent of one another or may be very diverse across countries. Furthermore, one may argue that these variables are also related to $\beta$. For instance, Wälde (2000) shows that the structure of education systems (elitist vs. egalitarian) may influence the skill intensity in production. In that sense the estimates here would support such an argument.

\footnotetext{
${ }^{31}$ Clearly, the problem of endogeneity of policy plays an important part in any cross-country growth analysis. See e.g. Rehme (2000).

${ }^{32}$ For instance, the total effect of TERP on RE is given by $-0.305+0.011 * 30.1=0.032$.
} 


\section{Concluding Remarks}

This paper argues that education directly affects growth and income inequality. In the model pre-tax and post-tax income inequality - measured by the Gini coefficient - as well as growth are first increasing and then decreasing in education. It is shown that a less efficient schooling system would require more redistributive education expenditure for a given level of education.

The data, which are based on consistent concepts for the measurement of inequality, provide some evidence that, when controlling for various factors such as initial income or fertility, long-run growth is higher for countries that (a) spend more on education, (b) have lower pre-tax and lower post-tax income inequality. The data also suggest that countries with a more productive, public education technology exhibit lower income inequality and higher growth. The paper does not find an indication that higher pre-tax or post-tax income inequality is good for growth in rich countries.

The consistent negative relation between pre-tax and post-tax inequality and growth in the data suggests that mixing Gini coefficients based on gross or on net incomes is most likely to produce an upward bias when measuring the effect of unadjusted measures of inequality on growth.

It also indicates that if a rich country spent more on public education it could raise growth and lower pre-tax and post-tax inequality, given its education technology.

However, a more precise disentanglement of the interaction between education policy and education technology, and their effects on growth and inequality appears to be called for and should be an interesting topic for further research. 


\section{A Technical Appendix}

\section{A.1 An Alternative OLG Set-Up}

The assumption of unequal capital ownership may also be justified as follows: Consider a twoperiod OLG model, where each agent has one offspring. Assume that establishing a firm requires a certificate which is related to education. At each moment the government picks some (new born, no matter whether the parents are high or low-skilled) people to be educated in period 1, who complete their degrees and open up their own firms in period 2. Those who are not picked go to the same school but attend lower level courses in period 1, and consequently work as low-skilled workers in period 2. This means that old (dying) high-skilled people only pass on capital to high skilled people, but never to low-skilled people, including their own (potentially) low skilled offspring. For if they did, the latter would not be allowed or be capable to operate the firm and capital would depreciate instantaneously. This would mean that passing on capital from a (dying) high-skilled entrepreneur to a low-skilled offspring who can only 'eat' the capital would not be in the interest of all the other agents. The other low-skilled (offspring) would not like it, because it would reduce their steady state wages. The high skilled (offspring) would not like it because they would have to share less capital. By assumption the representative government is taken to pass legislation to forbid such inefficient transfers.

\section{A.2 Technology}

By assumption $Y_{t}=A_{t} H_{t}^{\alpha} K_{t}^{1-\alpha}$, where the index of effective labour $H$ depends on labour requiring basic skills $(B)$ and labour requiring high skills $(S)$. Labour requiring basic skills is performed by high and low-skilled persons, $B=B\left(L_{l}, L_{h}\right)$, whereas high-skilled labour is only performed by high-skilled persons, $S=S\left(L_{h}\right)$. High and low-skilled people are perfect substitutes to each other when performing basic skill (routine) tasks, i.e. $B\left(L_{l}, L_{h}\right)=L_{l}+L_{h}$. Thus, high-skilled people also perform those routine tasks a low-skilled person may do. ${ }^{33}$ On the other hand, only high-skilled people can perform high-skilled tasks (labour) and for simplicity let $S\left(L_{h}\right)=L_{h}$. To capture the relationship between labour inputs assume $H=\left[B^{\rho}+\beta S^{\rho}\right]^{\frac{1}{\rho}}=$ $\left[\left(L_{h}+L_{l}\right)^{\rho}+\beta L_{h}^{\rho}\right]^{\frac{1}{\rho}}$, where $\beta$ measures the productivity with which tasks requiring high skills contributes to the generation of output. For $\rho<1$ labour requiring basic skills $(B)$ and labour requiring high skills $(S)$ are imperfect (less than perfect) substitutes. For ease of calculations let $\rho=\alpha<1$ which yields equation (1).

\footnotetext{
${ }^{33}$ For instance, Lindbeck and Snower (1996) show that firms may organize production so that people perform one particular task (Tayloristic organization) or various tasks (holistic organization). In the model only high-skilled people are capable of performing several tasks and firms use a mixture of Tayloristic and holistic organization.
} 


\section{A.3 Discrete Time Justification for $x=\left(\frac{\tau}{c}\right)^{\epsilon}$}

Equation (2) is compatible with many models that also use high-skilled labour as an input generating education. For instance, let $h_{t}$ denote the total stock of human capital in the economy in a discrete time model. Assume that human capital evolves according to $h_{t+1}=$ $f\left(G_{t}, K_{t}, h_{t}\right) h_{t}$ where new human capital $h_{t+1}$ is produced by non-increasing returns. See e.g. Azariadis and Drazen (1990). Here human capital formation would depend on the level of the stock of knowledge $h_{t}$, government resources provided for education $G_{t}$ and the tax base $r_{t} K_{t}$. The function $f(\cdot)$ governs the evolution of human capital. Assume that it is separable in the form $f\left(g\left(G_{t}, r_{t} K_{t}\right), h_{t}\right)$. Let $g=q\left[\frac{G_{t}}{r_{t} K_{t}}\right]=q(\tau)$ and for simplicity

$$
h_{t+1}=q(\tau) h_{t}^{\beta}, \text { where } q \geq 0, q^{\prime}>0, q^{\prime \prime} \leq 0,0<\beta<1
$$

where $\beta$ measures the productivity of the education sector and $q(\tau)$ captures the quality of education, depending on the government resources channelled into education. See, for example, eqns. (1), (2) in Glomm and Ravikumar (1992).

In the model human capital is carried discretely so $h_{t}=x_{t} N$. Normalize population by setting $N=1$. Then total human capital at date $t$ is given by $x_{t}$. In steady state $\bar{x}=x_{t}=x_{t+1}$ and so $\bar{x}=q(\tau)^{\frac{1}{1-\beta}}$. Next suppose that the quality of education is described by $q(\tau)=\tilde{\tau}^{\mu}$ where $\tilde{\tau}=\frac{\tau}{c}$ denotes the efficiently used resources in education and $0<\mu<0$. For non-increasing returns to scale it is necessary that $\mu+\beta \leq 1$. Let $\frac{\mu}{1-\beta} \equiv \epsilon$ then the more explicit set-up would be equivalent to (2) in steady state. As $\bar{x}_{\epsilon}<0$, any increase $\epsilon$ would mean that less human capital is generated in steady state. From non-increasing returns to scale it follows that $\mu \leq 1-\beta$ so that $\epsilon \leq 1$.

\section{A.4 Calibration}

Following Mankiw (1995) a high skilled worker is taken to earn three times as much as a low skilled worker. As the correlation between total government spending and the share of the population with tertiary education is quite high and given the data for the internal efficiency in tertiary education, the paper calibrates the model for the share of the population that has tertiary education. The mean in the sample is 0.15 . (See Table 7.) Thus, $\beta$ satisfies

$$
\left(1+0.15^{\alpha-1}\right)=\frac{w_{h}}{w_{l}}=3.0
$$

I assume $\alpha=0.7$ so that $\beta=1.13$. The capital/output ratio is taken be equal 3.0 so that

$$
\frac{Y}{K}=A\left(1+\beta x^{\alpha}\right)
$$

from which $A=0.26$. The discount factor $\rho$ is set at 0.01 . To get an estimate of the efficiency $c$ and of the productivity $\epsilon$ in schooling I have proceeded as follows:

The total government spending on education in terms of GDP (GEDU) is related to $\tau$ by $\tau=g_{x} \frac{Y}{r K}$ where $g_{x}$ is proxied by GEDU. Since $\frac{Y}{r K}=\frac{1}{1-\alpha}=\frac{10}{3}$ the data imply a value of 
$\tau=0.18$. I have then used the variable DROP to get an estimate of the efficiency of resources used in education. More precisely, I have taken $1-\frac{\mathrm{DROP}}{100}$ as a measure of $\frac{1}{c}$. From the regression $\ln$ TERP $=$ constant $+\beta_{1} \ln \left(\frac{\tau}{c}\right)$ the resulting $\hat{\beta}_{1}$ provides one with an estimate of $\epsilon$ in $x=\left(\frac{\tau}{c}\right)^{\epsilon}$ and is given by $\epsilon=0.58$.

I have then chosen $\phi$ so that the ratio of the Gini coefficients before and after taxes is 87 percent as in the data and so that their difference is around 4 percentage points. The $\phi$ necessary for that is $\phi=0.13$. Lastly, calibrating the growth rate required $\nu=3.65$ implying an intertemporal elasticity of substitution of around 27 percent.

\section{A.5 Unadjusted Inequality Measures}

Suppose you mix Gini coefficients for net and gross incomes to get an unadjusted inequality index $I$ which is then used in growth regressions.

$$
\begin{array}{rr}
\text { The model really run: } & \gamma_{i}^{u}=a+b G_{i}^{g}+c G_{i}^{n}+\epsilon_{i} \\
\text { The model run: } & \gamma_{i}^{u}=a^{\prime}+b_{i}^{\prime} I\left(G_{i}^{g}, G_{i}^{n}\right)+\epsilon_{i}^{\prime}
\end{array}
$$

where $\gamma_{i}^{u}$ is the residual of the regression of $\gamma_{i}$ on a vector of control variables. For simplicity assume that the control variables are not correlated or even orthogonal to the distributional variables. Commonly $\gamma_{i}^{u}$ is called the unexplained part of the growth rate. The latter is attempted to be explained by $I()$ in the models above. In general, $G_{i}^{g}=G_{i}^{n}+R_{i}^{A}$ for country $i$. This is true by the definition of $R_{i}^{A}$ as a measure of redistribution. Not every observation in $G_{i}^{g}$ may necessarily have a corresponding matching value of $G_{i}^{n}$ in the data set. However, values of $G_{i}^{n}$ are included by many NCV proponents in order to boost the number of observations. Now what is basically done is to create $I_{i}=G_{i}^{g}+G_{i}^{n}$. But this means $I_{i}=G_{i}^{g}+\tilde{G}_{i}^{g}-\tilde{R_{i}^{A}}$ where $\tilde{G}_{i}^{g}$ and $\tilde{R}_{i}^{A}$ may be unknown if there is no matching value for $G_{i}^{g}$ available in the data set. This implies that their estimate for $b^{\prime}$, call it $\hat{b}^{\prime}$, would contain information of the distribution of gross incomes, but also information on redistribution. Thus, the model they run is $\gamma_{i}^{u}=a+b G_{i}^{g}+c \tilde{G}_{i}^{g}-c \tilde{R_{i}^{A}}+\epsilon_{i}$ which puts a restriction on the effect that $\tilde{R_{i}^{A}}$ exerts. Relaxing it and noting that $\tilde{G}_{i}^{g}$ and $\tilde{R_{i}^{A}}$ are unknown, when there are no matching values in $G_{i}^{g}$, the regression is really run on values of known Gini coefficients for gross incomes, some unknown Gini values for gross income and some unknown values for redistribution. But consequently their 'true' model is

$$
\gamma_{i}^{u}=a+b G_{i}^{g}+c \tilde{G}_{i}^{g}+d \tilde{R_{i}^{A}}+\epsilon_{i}
$$

where $d=-c$. But this suggests the following argument: The estimates for $b$ and $c$ have often been found to be negative in earlier contributions. Furthermore, there is an empirical literature that shows that the estimate for $d$ is likely to be positive. Thus, you have an upward bias for the estimate of $b^{\prime}$. This bias may be so strong that you may even get a positive estimate for $b^{\prime}=b+c+d$, that is, $\hat{b^{\prime}} \geq 0$ is compatible with $\hat{b}<0, \hat{c}<0$ and $\hat{d}>0$. 


\section{References}

Acemoglu, D., "Why Do New Technologies Complement Skills? Directed Technical Change and Wage Inequality," Quarterly Journal of Economics, 1998, 113, 1055-1089.

Aghion, P., E. Caroli, and C. García-Peñalosa, "Inequality and Economic Growth: The Perspective of the New Growth Theories," Journal of Economic Literature, 1999, 37, $1615-1660$.

Alesina, A. and D. Rodrik, "Distributive Politics and Economic Growth," Quarterly Journal of Economics, 1994, 109, 465-490.

Amiel, Y. and F. A. Cowell, Thinking about Inequality, Cambridge, UK: Cambridge University Press, 1999.

Atkinson, A. B., "On the Measurement of Inequality," Journal of Economic Theory, 1970, 2, 244-263.

, The Economics of Inequality, 2nd ed., Oxford: Clarendon Press, 1983.

and A. Brandolini, "Promise and Pitfalls in the Use of "Secondary" Data-Sets: Income Inequality in OECD Countries as a Case Study," Journal of Economic Literature, 2001, 39, 771-799.

Autor, D., A. Krueger, and L. Katz, "Computing Inequality: Have Computers Changed the Labour Market," Quarterly Journal of Economics, 1998, 63, 1169-1213.

Azariadis, C. and A. Drazen, "Threshold Externalities in Economic Development," Quarterly Journal of Economics, 1990, 105, 501-526.

Banerjee, A., M. Marcellino, and C. Osbat, "Some Cautions on the Use of Panel Methods for Integrated Series of Macro-Economic Data," Working Paper 170, IGIER, Bocconi University, Milano 2000.

Banerjee, A. V. and E. Duflo, "Inequality and Growth: What Can the Data Say?," Working Paper 7793, NBER 2000.

Barro, R. J., Determinants of Economic Growth: A Cross-Country Empirical Study, Cambridge, Mass.: MIT Press, 1997.

"Inequality and Growth in a Panel of Countries," Journal of Economic Growth, 2000, 5, $5-32$.

and J.-W. Lee, "Sources of Economic Growth," Carnegie Rochester Conference Series on Public Policy, 1994, 40, 1-46.

Beaudry, P. and D. Green, "The Changing Structure of Wages in the US and Germany: What Explains the Difference?," Working Paper 7697, NBER 2000.

Bénabou, R., "Inequality and Growth," in B. S. Bernanke and J. J. Rotemberg, eds., NBER Macroeconomics Annual 1996, Cambridge and London: MIT Press, 1996, pp. 11-73.

__ , "Unequal Societies: Income Distribution and the Social Contract," American Economic Review, 2000, 90, 96-129.

Bertola, G., "Factor Shares and Savings in Endogenous Growth," American Economic Review, 1993, 83, 1184-1198.

, "Macroeconomics of Distribution and Growth," in A. B. Atkinson and F. Bourguignon, eds., Handbook of Income Distribution, Vol. 1, Amsterdam: Elsevier, 2000, pp. 477-540. 
Bound, J. and G. Johnson, "Changes in the Structure of Wages in the 1980s: An Evaluation of Alternative Explanations," American Economic Review, 1992, 82, 371-392.

Büttner, T. and B. Fitzenberger, "Central Wage Bargaining and Local Wage Flexibility: Evidence from the Entire Wage Distribution," Discussion Paper 98-39, ZEW, Mannheim 1998.

Caselli, F., "Technological Revolutions," American Economic Review, 1999, 89, 78-102.

, G. Esquivel, and F. Lefort, "Reopening the Convergence Debate: A New Look at Cross-Country Growth Empirics," Journal of Economic Growth, 1996, 1, 363-389.

Chiu, W. H., "Income Inequality, Human Capital Accumulation and Economic Performance," Economic Journal, 1998, 108, 44-59.

Ciccone, A., G. Peri, and D. Almond, "Capital, Wages, and Growth: Theory and Evidence," Working Paper 152, IGIER, Bocconi University, Milano 1999.

Cowell, F. A., Measuring Inequality, 2nd ed., Hemel Hempstead, UK: Prentice Hall/Harvester Wheatsheaf, 1995.

de la Fuente, A. and R. Doménech, "Human Capital in Growth Regressions: How Much Difference Does Data Quality Make?," Working Paper 262, OECD 2000.

Deininger, K. and L. Squire, "A New Data Set Measuring Income Inequality," World Bank Economic Review, 1996, 10, 565-591.

_ _ and _ _ "New Ways of Looking at Old Issues: Inequality and Growth," Journal of Development Economics, 1998, 57, 259-287.

Easterly, W. and S. Rebelo, "Fiscal policy and economic growth. An empirical investigation," Journal of Monetary Economics, 1993, 32, 417-458.

Eicher, T. and C. García-Peñalosa, "Inequality and Growth: The Dual Role of Human Capital in Development," Journal of Development Economics, 2001, 66, 173-197.

Fernandez, R. and R. Rogerson, "Public Education and Income Distribution: A Dynamic Quantative Evaluation of Education-Finance Reform," American Economic Review, 1998, 88, 813-833.

Fields, G. S., "Measuring inequality change in an economy with income growth," Journal of Development Economics, 1987, 91, 611-625.

Figini, P., "Inequality and Growth Revisited," Discussion Paper 99/2, Trinity College, Dublin, Ireland 1999.

Forbes, K. J., "A Reassessment of the Relationship between Inequality and Growth," American Economic Review, 2000, 90, 869-887.

Galor, O. and D. Tsiddon, "Technological Progress, Mobility, and Economic Growth," American Economic Review, 1997, 87, 363-382.

and J. Zeira, "Income Distribution and Macroeconomics," Review of Economic Studies, 1993, 60, 35-52.

Glomm, G. and B. Ravikumar, "Public versus Private Investment in Human Capital: Endogenous Growth and Income Inequality," Journal of Political Economy, 1992, 100, $818-834$.

Goodspeed, T. J., "Education Spending, Inequality and Economic Growth: Evidence from US States," mimeo, Hunter College - CUNY, New York 2000. 
Johnson, G. E., "Subsidies for Higher Education," Journal of Labor Economics, 1984, 2, 303-318.

Jovanovic, B., "Growth Theory," Working Paper 7468, NBER 2000.

Katz, L. F. and K. M. Murphy, "Changes in Relative Wages, 1963-1987: Supply and Demand Factors," Quarterly Journal of Economics, 1992, 107, 35-78.

Krusell, P., L. E. Ohanian, J.-V. Ríos-Rull, and G. L. Violante, "Capital-Skill Complementarity and Inequality: A Macroeconomic Analysis," Econometrica, 2000, 68, 10291053.

Kuznets, S., "Economic growth and income inequality," American Economic Review, 1955, $45,1-28$.

Lambert, P. J., The Distribution and Redistribution of Income: A Mathematical Analysis, 2nd ed., Manchester, UK: Manchester University Press, 1993.

Lee, W. and J. E. Roemer, "Income Distribution, Redistributive Politics, and Economic Growth," Journal of Economic Growth, 1998, 3, 217-240.

Li, H. and H.-F. Zou, "Income Inequality is Not Harmful for Growth: Theory and Evidence," Review of Development Economics, 1998, 2, 318-34.

Lindbeck, A. and D. J. Snower, "Reorganization of Firms and Labour-Market Inequality," American Economic Review, Papers and Proceedings, 1996, 86, 315-321.

Mankiw, N. G., "The Growth of Nations," Brookings Papers on Economic Activity, 1995, 1, $275-310$.

McCloskey, D. N., "The Loss Function Has Been Mislaid: The Rhetoric of Significance Tests," American Economic Review, 1985, 75, 201-205.

and S. T. Ziliak, "The Standard Error of Regressions," Journal of Economic Literature, 1996, 34, 97-114.

Murphy, K. M., W. C. Riddel, and P. M. Romer, "Wages, Skills, and Technology in the United States and Canada," Working Paper 6638, NBER 1998.

Perotti, R., "Political Equilibrium, Income Distribution, and Growth," Review of Economic Studies, 1993, 60, 755-776.

__ , "Income distribution and investment," European Economic Review, 1994, 38, 827-835.

_ _ "Growth, Income Distribution, and Democracy: What the Data Say," Journal of Economic Growth, 1996, 1, 149-187.

Persson, T. and G. Tabellini, "Is Inequality Harmful for Growth?," American Economic Review, 1994, 84, 600-621.

Rehme, G., "Education, Economic Growth and Personal Income Inequality Across Countries," Working Paper ECO 99/42, European University Institute, Florence, Italy 1999.

_ _ "Economic Growth and (Re-)Distributive Policies: A Comparative Dynamic Analysis," Working Paper ECO 00/13, European University Institute, Florence, Italy 2000.

Romer, P. M., "Increasing Returns and Long-Run Growth," Journal of Political Economy, 1986, 94, 1002-1037.

Saint-Paul, G. and T. Verdier, "Inequality, Redistribution and Growth: A Challenge to the Conventional Political Economy Approach," European Economic Review, 1996, 40, 719-728. 
Sala-i-Martin, X., "A Positive Theory of Social Security," Journal of Economic Growth, 1996, $1,277-304$

Shorrocks, A. F., "Ranking Income Distributions," Economica, 1983, 50, 1-17.

Summers, R. and A. Heston, "The Penn World Table (Mark 5): An Expanded Set of International Comparisons, 1950-1988," Quarterly Journal of Economics, 1991, 106, 327368.

Temple, J., "The New Growth Evidence," Journal of Economic Literature, 1999, 37, 112-156.

Tinbergen, J., Income Distribution: Analysis and Policies, Amsterdam: North-Holland, 1975.

Wälde, K., "Egalitarian and Elitist Education Systems as the Basis for Inernational Differences in Wage Inequality," European Journal of Political Economy, 2000, 16, 445-468.

Zweimüller, J., "Redistribution, Inequality and Growth," Empirica, 2000, 27, 1-20. 


\section{Data Appendix}

\section{Data Sources}

- Barro and Lee (1994). Web site: www.nber.org/data/.

- Summers and Heston (1991): Penn World Table (Mark 5.6). Web site: www.nber.org/data/.

- OECD Education Database: Education at a Glance 1998, Table A1.

- OECD Education Database: Education at a Glance 2000, Table C4.1.

- Deininger and Squire (1996). Web site: www.worldbank.org/research/growth/dddeisqu.htm.

- Luxembourg Income Study. Web site: www.lisproject.org.

- World Income Inequality Database (WIID). Web site: www.wider.unu.edu/wiid/wiid.htm

\section{Definition of variables ${ }^{34}$}

G70-90 Average growth rate of real GDP per capita for the period 1970-1990 in percentage points, where G70-90 $=\frac{\ln y_{T}-\ln y_{0}}{T}$ and $y_{T}$ denotes per capita GDP at final date $T$. (Source: Penn World Tables, Mark 5.6.)

SECP Percentage of the population from 25 to 64 years of age who have attained at least upper secondary education, 1996. (Source: OECD, 1998)

TERP Percentage of the population from 25 to 64 years of age who have attained at least universitylevel education, 1996. (Source: OECD, 1998)

LIS.G Average Gini coefficient for gross income of households (adjusted for household size by the square root of the number of household members) for the period 1970-1990. (Source: Luxembourg Income Study)

AIHG Average Gini coefficient for gross income of households for the period 1970-1990 (Source: WIID)

LIS.N Average Gini coefficient for net income of households (adjusted for household size by the square root of the number of household members) for the period 1970-1990. (Source: Luxembourg Income Study)

AIHN Average Gini coefficient for net income of households for the period 1960-1990 (Source: WIID)

LY70 Natural logarithm of the level of real GDP per capita in 1970. (Source: Penn World Tables, Mark 5.6; Variable: RGDPL, i.e. real GDP per capita in 1985 international prices.)

AFERT Average fertility rate (children per woman) for the period 1960-84. (Source: Barro-Lee).

GEDU Government expenditure on education as a fraction of GDP for the period 1960-1985 in percentage points. (Source: Barro-Lee)

CVLIB Gastil's index of civil liberties (from 1 to $7 ; 1=$ most freedom) for the period 1972-1989. (Source: Barro-Lee)

DROP Drop-out rates at the university-level tertiary education from 1985-96. (Source: OECD 2000)

\footnotetext{
${ }^{34}$ A more detailed description of the data and the results is provided at: http://www.tu-darmstadt.de/ rehme/project/data01.htm.
} 
Table 7: Sample based on LIS

\begin{tabular}{|c|c|c|c|c|c|c|c|c|c|c|c|}
\hline & G70-90 & LIS.G & LIS.N & $\mathrm{RE}$ & SECP & TERP & GEDU & LY70 & AFERT & CVLIB & DROP \\
\hline Finland & 2.75 & 26.04 & 20.89 & 5.15 & 66.79 & 13.52 & 5.76 & 9.00 & 1.97 & 1.94 & 25 \\
\hline Norway & 3.09 & 26.94 & 22.89 & 4.05 & 81.59 & 15.57 & 6.26 & 8.99 & 2.32 & 1.00 & $30^{*}$ \\
\hline Sweden & 1.57 & 27.03 & 22.32 & 4.71 & 74.20 & 13.37 & 7.10 & 9.28 & 1.96 & 1.00 & $30^{*}$ \\
\hline Denmark & 1.82 & 28.06 & 24.37 & 3.69 & 66.09 & 15.25 & 6.27 & 9.18 & 2.01 & 1.00 & 33 \\
\hline Germany & 2.09 & 29.16 & 25.80 & 3.37 & 81.47 & 13.10 & 4.03 & 9.15 & 1.89 & 1.64 & 28 \\
\hline Netherlands & 1.74 & 29.47 & 25.53 & 3.94 & 62.54 & 22.54 & 6.95 & 9.13 & 2.27 & 1.00 & 30 \\
\hline France & 2.07 & 30.38 & 28.77 & 1.61 & 60.22 & 9.73 & 4.37 & 9.13 & 2.54 & 1.86 & 45 \\
\hline U.K. & 2.19 & 31.98 & 28.76 & 3.22 & 76.31 & 12.77 & 5.25 & 9.05 & 2.26 & 1.00 & 19 \\
\hline Canada & 2.64 & 32.27 & 29.03 & 3.24 & 76.41 & 17.31 & 6.82 & 9.22 & 2.36 & 1.00 & $30^{*}$ \\
\hline Australia & 1.47 & 34.30 & 29.25 & 5.05 & 56.95 & 14.84 & 4.73 & 9.28 & 2.60 & 1.00 & 35 \\
\hline Switzerland & 1.21 & 34.40 & 31.90 & 2.50 & 80.17 & 9.53 & 4.50 & 9.47 & 1.98 & 1.00 & 26 \\
\hline U.S.A. & 1.66 & 36.07 & 32.07 & $4.28^{1}$ & 85.66 & 25.80 & 5.94 & 9.47 & 2.21 & 1.00 & 37 \\
\hline Ireland & 3.07 & 37.04 & 32.47 & 4.58 & 50.22 & 10.74 & 5.05 & 8.52 & 3.58 & 1.22 & 23 \\
\hline Min. & 1.21 & 26.04 & 20.89 & 1.61 & 50.22 & 9.53 & 4.03 & 8.52 & 1.89 & 1.00 & 19 \\
\hline Max. & 3.09 & 37.04 & 32.46 & 5.15 & 85.66 & 25.80 & 7.10 & 9.47 & 2.60 & 1.94 & 45 \\
\hline Mean & 2.11 & 31.03 & 27.23 & 3.80 & 70.66 & 14.80 & 5.62 & 9.14 & 2.30 & 1.21 & 30.1 \\
\hline $\mathrm{SD}$ & 0.61 & 3.67 & 3.88 & 1.02 & 10.98 & 4.80 & 1.04 & 0.24 & 0.44 & 0.36 & 7.6 \\
\hline
\end{tabular}

Ordered in ascending order of the Gini coefficients for gross income of households LIS.G. The dropout rates for Norway, Sweden and Canada are based on an average when excluding these countries from the sample. ${ }^{1}$ - based on time matching Gini values only. See the data appendix for a justification and a discussion of its implications. 